\title{
Fenología de la gametogénesis, madurez de conceptáculos, fertilidad y embriogénesis en Durvillaea antarctica (Chamisso) Hariot (Phaeophyta, Durvillaeales)
}

\author{
Phenology of gametogenesis, maturity of conceptacles, fertility and embryogenesis in \\ Durvillaea antarctica (Chamisso) Hariot (Phaeophyta, Durvillaeales) \\ Gloria Collantes, Ana Merino y Verónica Lagos \\ Universidad de Valparaíso, Facultad de Ciencias del Mar. Casilla 13 - D, Viña del Mar, Chile. \\ gloria.collantes@uv.cl
}

\begin{abstract}
Resumen.- Durvillaea antarctica se caracteriza por presentar al igual que los representantes de las Fucales, una historia de vida sin generación gametófita de vida libre y por poseer reproducción oógama. En este trabajo mediante el uso de técnicas de microscopía óptica, se describe la fenología de la gametogénesis, estados de madurez de los conceptáculos, fertilidad y embriogénesis de $D$. antarctica de caleta Montemar Chile central $\left(32^{\circ} 57^{`} \mathrm{~S}-71^{\circ} 33^{\prime} \mathrm{W}\right)$. De acuerdo a los resultados obtenidos, las etapas de la gametógenesis son indicadoras del estado de madurez de los conceptáculos y el número de estratos de conceptáculos señala el número de períodos reproductivos de los ejemplares. En un seguimiento anual la población intermareal de $D$. antarctica presentó un período vegetativo y/o reposo reproductivo en verano y una dinámica de maduración y fertilidad desde otoño a principios de primavera; en estos ejemplares los conceptáculos estuvieron dispuestos en un estrato (98\%). Especímenes recolectados en una varazón invernal presentaron estados vegetativos y reproductivos propios de la madurez y fertilidad con $1(61 \%), 2(36 \%)$ y $3(3 \%)$ estratos de conceptáculos, que indican diferencias con la población intermareal relacionadas al número de períodos reproductivos y a la probable existencia en los ejemplares varados de un componente de frondas submareales, hecho que amerita efectuar en estas últimas estudios fenológicos similares a los de la población intermareal. La información obtenida completa la historia de vida de D. antarctica y proporciona bases biológicas para su manejo y futuro cultivo. $D$. antarctica es uno de los recursos algales chilenos importante como alimento y materia prima para la industria de alginatos.

Palabras clave: Fenología, gametogénesis, madurez de conceptáculos, fertilidad, embriogénesis, Durvillaea antarctica.
\end{abstract}

\begin{abstract}
Durvillaea antarctica has a life history similar to Fucales, characterized by lacking a free-living gametophyte generation and in having oogamous reproduction. Using techniques of light microscopy observations were made on phenology of gametogenesis, fertilization, maturity of conceptacles and embryogenesis of D. antarctica from Montemar cove, central Chile $\left(32^{\circ} 57^{`} \mathrm{~S}-\right.$ $\left.71^{\circ} 33^{\prime} \mathrm{W}\right)$. Degree of development of gametogenesis indicated maturity stages of conceptacles. Number of conceptacle layers indicated number of annual reproductive periods. During summer time, intertidal plants showed a vegetative or a rest period. From Autumn to early Spring, intertidal plants with one layer of conceptacles (98\%), showed the gradual sequence of maturity and fertility periods. During Winter, drift fronds with 1 (61\%), 2 (36\%) and $3(3 \%)$ layers of conceptacles showed different reproductive periods of maturity and fertility. Drift fronds seem to have components of subtidal fronds and further studies on reproductive phenology similar those undertaking in intertidal plants are needed. Life history information generated may well be applied to improve management and future culture of this resource. D. antarctica is an important Chilean resource having industrial potential.
\end{abstract}

Keywords: Phenology, gametogenesis, maturity of conceptacles, fertility, embryogenesis, Durvillaea antarctica.

\section{Introducción}

Durvillaea Bory (1826) es un alga parda del Orden Durvillaeales. Se reconocen cuatro especies, todas presentes en aguas frías y en lugares expuestos del sur de Australia, Nueva Zelanda, extremo austral de América e islas subantárticas (Hay 1979). Durvillaea fue primeramente clasificado dentro del Orden Fucales por Chamisso, en Choris (1822), quien llamó a la especie, Fucus antarcticus, debido a la característica presencia en la fronda de los ejemplares maduros, de conceptáculos con oogonios y anteridios. Posteriormente, atributos morfológicos hacen que Hariot (1892), la determine con el nombre de Durvillaea antarctica (Chamisso) Hariot. Actualmente a Durvillaea se le excluye del Orden Fucales y se le incluye en el Orden Durvillaeales, por el origen particular del desarrollo de los conceptáculos (Petrov, 1965, 1967), crecimiento 
difuso y no apical (Nizamuddin 1968), células superficiales con dos cloroplastos alargados, a diferencia de las Fucales donde son numerosos y discoidales (Roberts 1979).

El talo de Durvillaea antarctica consiste de una gran lámina de color café oscuro o pardo verdoso, que alcanza tamaños de 15 o más metros de longitud. Morfológicamente consta de un disco macizo para la adhesión al sustrato, desde el cual se origina un estipe cilíndrico, cuyo extremo se aplana y ensancha en sentido apical para formar la fronda o lámina. Esta es alargada y entera en juveniles, dividida en porciones de ancho dispar en adultos (Alveal et al. 1990b).

La lámina de $D$. antarctica está parcialmente o totalmente inflada en un tejido de apariencia de panal de abeja. El margen es indiferenciado. En especímenes pequeños la médula presenta numerosos espacios tipo vacuolas pequeñas y una médula central con hifas simples y ramificadas entretejidas sueltamente a menudo en ángulos rectos al plano de flotación. Las paredes de las células corticales y de las hifas están muy gelatinizadas (Hay 1979).

En Chile, D. antarctica se distribuye desde Coquimbo (29 $\left.58^{\prime} \mathrm{S}-71^{\circ} 22^{\prime} \mathrm{W}\right)$ hasta la zona del

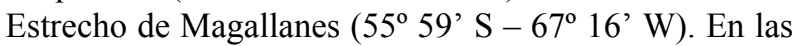
regiones central y centro sur habita junto a Lessonia nigrescens en sustratos rocosos de niveles altos del sublitoral expuesto al oleaje, pero hacia el sur $D$. antarctica se hace dominante. Se encuentra también en Nueva Zelanda, Argentina en Tierra del Fuego, islas Malvinas, islas Heard, islas McDonald (Ramírez \& Santelices 1991) e islas Kerguelen (Delepine \& Asensi 1976). Una forma submareal de D. antarctica sin celdillas tipo panal de abejas de las islas Macquarie (Ricker 1987) ha sido estudiada por Klemm \& Hallam (1988). Una forma de D. antarctica con láminas sólidas probablemente equivalente a la de las islas Macquarie ha sido colectada en el sur de Chile (Cheshire, no publicado).

La historia de vida de Durvillaeales es semejante a la del Orden Fucales (Maier \& Clayton 1989); las primeras observaciones realizadas en $D$. willana y $D$. antarctica de Nueva Zelanda indican la carencia de una generación gametófita libre y reproducción oógama y describen detalladamente los conceptáculos femeninos maduros y sus oogonios (Naylor 1953). El talo es diploide y en $D$. potatorum de las costas australianas, se ha descrito la oogénesis y la ubicación de la meiosis (Maier \& Clayton 1989). La fenología de la gametogénesis no ha sido descrita para ninguna de las especies del género.
Estudios detallados de fecundación sólo se conocen en Fucales, involucrando la fusión de un huevo grande no mótil y un pequeño espermatozoide biflagelado (Pollock 1970). La superficie del huevo es suave después de la fertilización (Callow et al. 1978), dándose inicio a la formación de la pared celular (Pollock 1970, Quatrano \& Stevens 1976). La fenología de la fecundación de las oosferas y el desarrollo ontogenético de los cigotos en Durvillaeales no han sido aún descritos.

Aunque en Chile existen estudios sobre su ecología y distribución vertical y geográfica (Guiler 1959, Alveal 1970, Santelices et al. 1977, Santelices 1989), biología poblacional, fenología reproductiva (Westermeier et al. 1994, Collantes et al. 1997), descripción y evaluación como recurso (Alveal et al. 1990a, 1990b), valor nutritivo y aportes de fibra dietética (Pak \& Araya 1996), efectos de la explotación humana en sus poblaciones (Castilla \& Bustamante 1989, Bustamante \& Castilla 1990), morfología y reproducción (Buschmann 1982), ultraestructura de la gametogénesis, fecundación y embriones (Paredes 1998), faltan aún bases biológicas para determinar estados de madurez reproductiva y capacitación de gametos. En $D$. antarctica de las costas sur y centro de Chile, el período fértil se localiza entre otoño y primavera (Alveal et al. 1990a, Bushmann 1982, Westermeier et al. 1994, Collantes et al. 1997, Merino 2000, Lagos 2001), aunque existen datos de la presencia de frondas fértiles durante el verano (enero) en playa los Molles localidad de Chile central (Santelices et al. 1980). D. antarctica es uno de los recursos algales chilenos con potencial de cultivo (Norambuena 1996), importante como alimento y materia prima para la industria de alginatos. Durante los últimos 10 años su recolección desde praderas naturales ha sido muy variable con un máximo de 4567 ton y un mínimo de 464 ton en 1994 y 1999 respectivamente (SERNAP 1994, 1999). En este contexto, el objetivo de este trabajo es caracterizar en $D$. antarctica, la fenología de la gametogénesis, estados de madurez de conceptáculos, fecundación y embriogénesis.

\section{Materiales y Métodos}

Los ejemplares de D. antarctica utilizados en este estudio provinieron de la localidad caleta Montemar $\left(32^{\circ} 57^{\prime} \mathrm{S}-71^{\circ} 33^{\prime} \mathrm{W}\right)$.

En el mes de octubre de 1997 se seleccionaron en el intermareal 20 reclutas de $D$. antartica, $5-10 \mathrm{~cm}$ de longitud para seguir macroscópicamente la formación de los conceptáculos, estructura indicadora del estado 
reproductivo. Los ejemplares seleccionados carecían de signos externos de desarrollo de conceptáculos.

Para la determinación de frondas vegetativas y reproductivas, estados de madurez y número de estratos de conceptáculos, desde marzo a octubre de 1997 y febrero y marzo de 1998, en un total de 100 especímenes se extrajo mensualmente diez trozos $(10$ $\mathrm{cm})$ de $D$. antarctica, en 10 ejemplares intermareales mayores a $50 \mathrm{~cm}$ de longitud con y sin signos de desarrollo de conceptáculos a ojo desnudo. El período de estudio fue seleccionado de acuerdo al período reproductivo y vegetativo determinado para la localidad de Montemar (Collantes et al. 1997) y el criterio tiempo de desarrollo de conceptáculos según Naylor (1953), que indica menos de un año. El tamaño de los especímenes seleccionados, en base de estudios sobre la frecuencia relativa de talos reproductivos de $D$. antarctica, que demostraron que cerca del $20 \%$ de la población reproductiva en cualquier tiempo estuvo constituida de ejemplares con talos inferiores a $75 \mathrm{~cm}$ de longitud y que juveniles marcados alcanzaron tales longitudes $( \pm 25 \mathrm{~cm} ; \mathrm{n}=50)$ llegando a ser reproductivos dentro de seis meses ( Santelices et al. 1980). En el mes de julio del año 2001, trozos similares se obtuvieron desde 101 especímenes mayores a $1 \mathrm{~m}$ de longitud, varados en caleta Montemar después de una fuerte marejada.

Para la determinación de la fertilidad, desde mayo de 1999 a septiembre de 2000, en un total de 152 especímenes se extrajeron mensualmente $3-25$ trozos de frondas intermareales accesibles, con conceptáculos mayores a $50 \mathrm{~cm}$ de longitud; en el mes de junio del año 2000, trozos similares se obtuvieron desde 55 ejemplares mayores a $1 \mathrm{~m}$ de longitud, varados en caleta Montemar después de una fuerte marejada.

En el laboratorio se efectuaron cortes longitudinales a mano alzada a través de la subcorteza de los explantes de ejemplares intermareales y varados, para determinar bajo microscopio óptico estructuras celulares indicadoras de: estado vegetativo (ausencia de conceptáculos), estado reproductivo (presencia de conceptáculos) y sexo de los ejemplares (presencia de anteridios $\mathrm{u}$ oogonios) (Collantes et al. 1997).

Para la caracterización de indicadores celulares de la gametogénesis se hicieron cortes transversales de la corteza y subcorteza de ejemplares vegetativos y reproductivos intermareales y varados, los cuales fueron fijados en $3: 1$ de etanol, ácido glacial acético y cortadas en un micrótomo de congelación Leitz Wetzlar. Parte de este material fue teñido con azul de toluidina y reactivo de Shiff mediante el método de Feulgen. Las observaciones se realizaron en un microscopio Nikon
Labophot, equipado con cámara fotográfica y las mediciones con un micrómetro ocular Nikon CF10x/14.

Para la caracterización de estados indicadores de madurez de conceptáculos, se extrajeron a mano alzada con hojas de afeitar, porciones de corteza y subcorteza en sentido longitudinal de aproximadamente $1 \mathrm{~cm}^{2}$. Estos trozos fueron fijados en $3: 1$ de etanol, ácido glacial acético y cortados transversalmente en secciones de $40 \mu \mathrm{m}$ de grosor, en un micrótomo de congelación Leitz Wetzlar. Estas fueron teñidas con azul de toluidina al $1 \%$, observadas y fotografiadas en un microscopio Nikon Labophot equipado con cámara fotográfica y micrómetro ocular Nikon CF10x/14.

Para la determinación de los estados de madurez de los conceptáculos se elaboró una escala numérica, que describió la secuencia de los diferentes estados reproductivos, según el grado de desarrollo de anteridios u oogonios (forma, tamaño y número de células diferenciadas). Para la caracterización de indicadores celulares de la fecundación, cigotos y de la embriogénesis, desde mayo a julio 1999, se adecuó en laboratorio, la metodología de cultivo descrita por Quatrano (1980), la cual básicamente consistió en inducir separadamente, a partir de trozos de explantes maduros masculinos y femeninos, mediante cambios de temperatura $\left(6-18^{\circ} \mathrm{C}\right)$ o desecación y humectación, en agua de mar filtrada y estéril, la liberación de espermatozoides y oosferas. Las suspensiones de gametos masculinos y femeninos obtenidas separadamente, fueron mezcladas entre sí para inducir la fecundación artificialmente. Con el mismo fin la fecundación también fue obtenida mediante la técnica tradicional de cultivo; desde agosto 1999 a septiembre 2000, se realizaron incubaciones in vitro de trozos de corteza femeninos y masculinos, ubicados próximos entre sí (cruzamientos), en cápsulas de Petri plásticas de $5 \mathrm{~cm}$ de diámetro. Los cigotos obtenidos por ambos métodos, se fijaron sobre cuatro cubre objetos dispuestos en el fondo de las cápsulas, incubados en medio Provasoli, $13{ }^{\circ} \mathrm{C}, 30-40 \mu \mathrm{mol} \mathrm{m} \mathrm{s}^{-1}, 12: 12 \mathrm{~h}$ luz:oscuridad. Para impedir contaminación de los cultivos por bacterias y diatomeas se adicionó cloramfenicol $(50 \mu \mathrm{g} / \mathrm{ml})$ y óxido de germanio $(5-10 \mu \mathrm{g} / \mathrm{ml})$. Los cigotos y embriones obtenidos fueron controlados cada $24 \mathrm{~h}$ durante los primeros tres días y cada siete días durante 8 semanas; recambios de medio nutritivo se realizaron semanalmente. Para la determinación de indicadores celulares de fecundación, se usaron los siguientes caracteres: ausencia de pared celular y evidencia de una zona nuclear clara ("ojo") en oosferas sin fecundación; presencia de halo de fecundación y evidencia de dos zonas nucleares claras ("ojos") en los cigotos. En la caracterización de los embriones se siguieron patrones de desarrollo de la polaridad. Los indicadores pre y 
post fecundación se contabilizaron a las $72 \mathrm{~h}$ de incubación, en un cubreobjeto elegido al azar, efectuando bajo microscopio óptico un recorrido por el margen superior y lateral izquierdo, abarcando el campo visual del objetivo x20 del microscopio Nikon Labophot.

Los resultados de la secuencia temporal de indicadores celulares vegetativos y reproductivos se analizaron mediante la confección de tablas de contingencia de doble entrada, cálculo de porcentajes, test $\mathrm{G}$ de independencia y test Chi cuadrado con un nivel de significancia del 1\% (Sokal \& Rohlf 1979).

Para determinar la densidad de ejemplares adultos presentes en el intermareal de caleta Montemar, se contabilizó su número en el mes de diciembre de 2000. Se consideraron sólo los especímenes mayores a $50 \mathrm{~cm}$, con signos de desarrollo de conceptáculos a ojo desnudo. La medición del área total de distribución de ejemplares fue realizada mediante el programa Autocad 2000. Con los datos de densidad del área de recolección y tamaño del área total de distribución se estimó el tamaño total de la población, el cual también fue calculado retrospectivamente para el promedio anual del número total de ejemplares de la misma área de recolección en 1993/94 (Collantes et al. 1997).

\section{Resultados}

\section{Caracterización de trozos de ejemplares vegetativos y reproductivos}

Los trozos seleccionados de las frondas o látigos de especímenes intermareales mayores de $50 \mathrm{~cm}$ se encontraron en estado vegetativo o reproductivo. Los vegetativos se caracterizaron por ser de sección plana (ancho $<1 \mathrm{~cm}$ ), presentar una textura lisa y suave al tacto, meristoderma constituido por una capa de células poliédricas, corteza con ocho a diez corridas de células alargadas dispuestas ordenadamente en una matriz mucilaginosa y médula con varios estratos de células irregulares dispuestas entre espacios menores a mayores hacia el interior. Los trozos reproductivos se caracterizaron por ser de sección plana a circular (ancho $>1 \mathrm{~cm}$ ) según sean de frondas ensanchadas o de los látigos, de textura ligeramente áspera, debido a la presencia de los ostíolos de los conceptáculos (50 a 150 $\mu \mathrm{m}$ de diámetro) separados entre sí por 800 a $900 \mu \mathrm{m})$ y esparcidos en la superficie de ambos lados de frondas y látigos (Fig. 1).

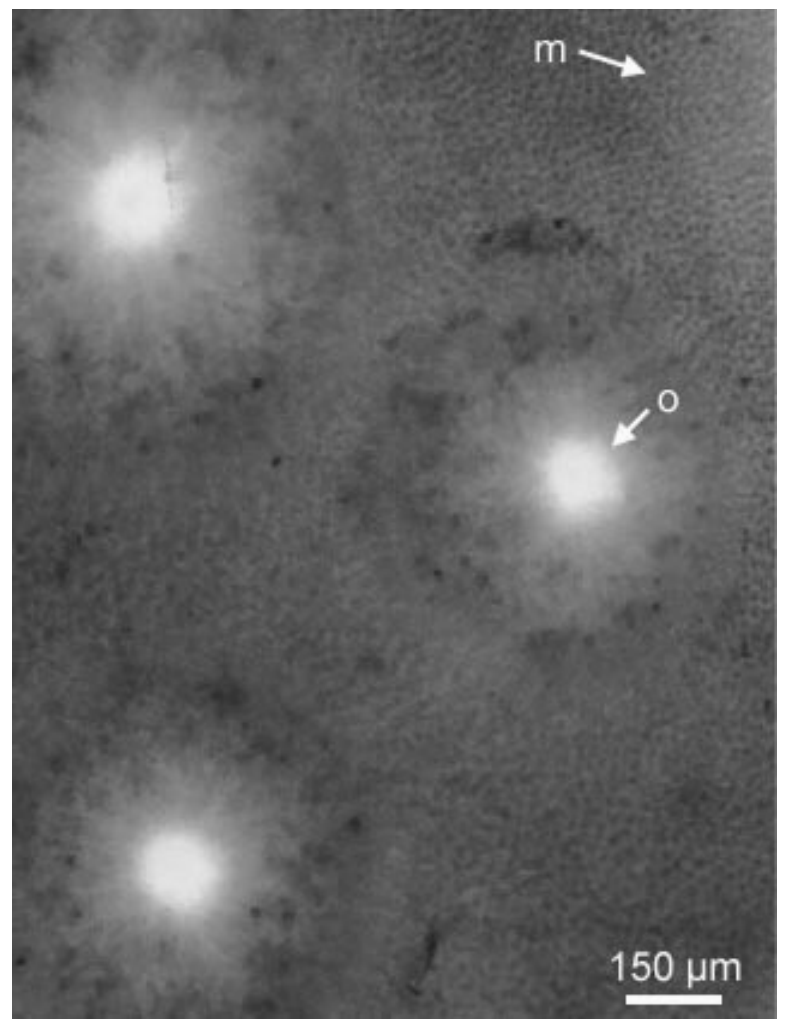

Figura 1

D. antarctica. Visión superficial fronda reproductiva, meristoderma (m), ostíolos de los conceptáculos (o). $40 \mathrm{x}$

D. antarctica. Reproductive frond surface view, meristoderm (m), ostioles of conceptacles (o). $\mathrm{x} 40$ 
En vista superficial y en secciones transversales fue común encontrar un delicado retículo, acorde al contorno de la pared celular del patrón de disposición de las células del meristoderma, adherido o desprendiéndose de la superficie de los ejemplares, que pareciera corresponder a un proceso natural para limpiar de epífitas la superficie de los mismos (Fig. 2). La corteza presentó 10 a 15 corridas de células alargadas dispuestas ordenadamente en una matriz mucilaginosa y médula con varios estratos de células irregulares dispuestas entre espacios menores a mayores hacia el interior, formando en el centro la característica estructura de panal. Los conceptáculos se ubicaron en la corteza y estratos iniciales de la médula.

\section{Caracterización de la ontogenia de los conceptáculos}

De los 20 ejemplares juveniles $(<10 \mathrm{~cm})$ presentes en las áreas seleccionadas durante el mes de octubre de

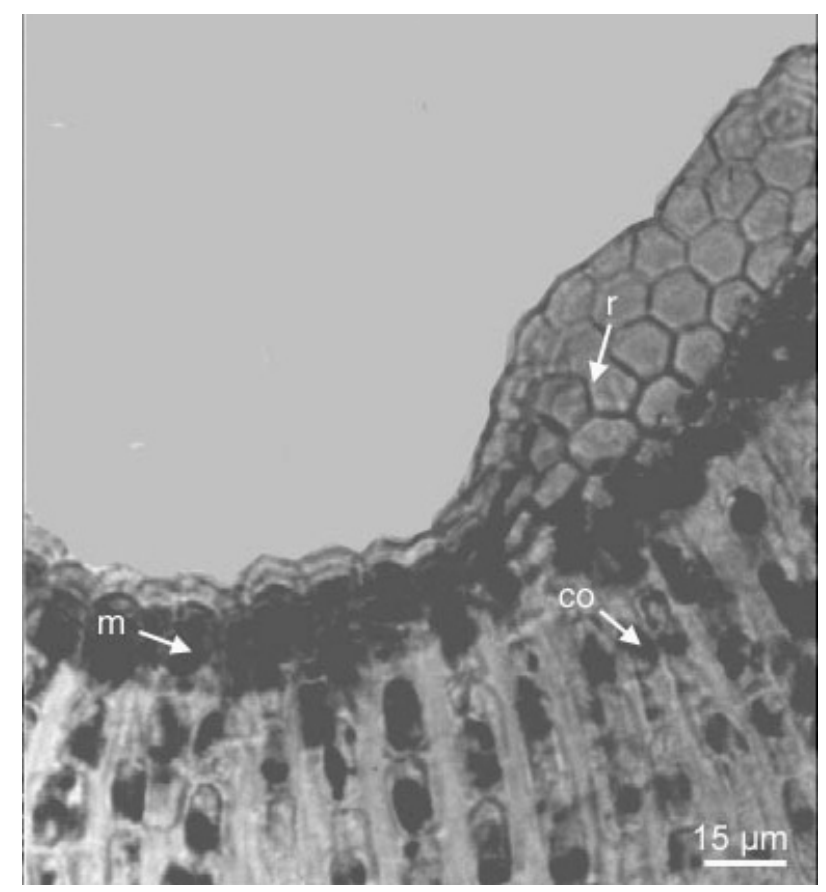

Figura 2

D. antarctica. Corte transversal fronda reproductiva, retículo superficial (r), meristoderma (m), corteza (co). $400 \mathrm{x}$

D. antarctica. Transversal section of reproductive frond, surface reticulate layer (r), meristoderm (m), cortex (co). x 400
1997 para el seguimiento de la diferenciación y maduración de conceptáculos, sólo sobrevivieron a marzo del año siguiente 6 de ellos, alcanzando en el mes de mayo de 1998 longitudes superiores a $60 \mathrm{~cm} \mathrm{e}$ indicios de conceptáculos por las finas puntuaciones color amarillo claro en zonas marginales de la fronda media. La observación de cortes transversales demostró que el desarrollo inicial de los conceptáculos se caracterizó por una diferenciación celular, aumento en número de un grupo de células localizadas entre la subcorteza y la médula (Fig. 3). Divisiones celulares oblicuas originaron ramificaciones, convergiendo las filas de células laterales hacia las filas centrales de corteza y de médula, conformando el centro del conceptáculo, en el cual por reorganización celular se dio comienzo en su base a un lumen, primero irregular después ovoide o cónico que se abrió en sentido longitudinal avanzando hacia la corteza, formando el cuello o garganta que se comunica con el exterior por el ostíolo cuando los ejemplares maduran.

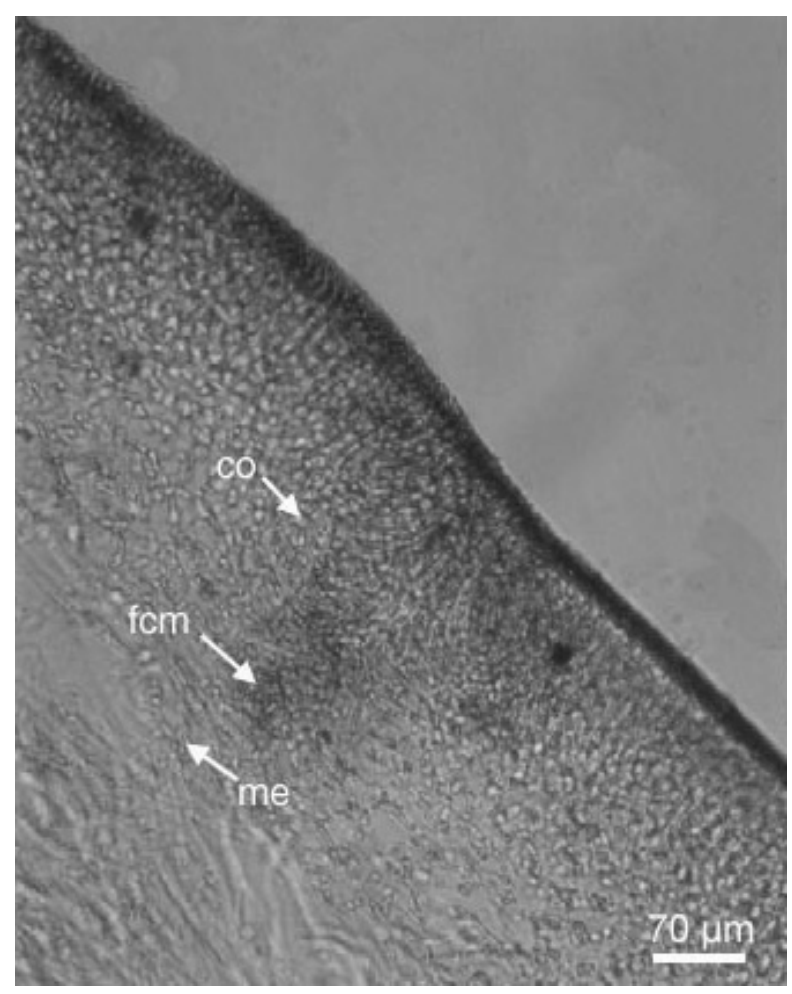

Figura 3

D. antarctica. Corte transversal, mostrando el desarrollo inicial del conceptáculo, corteza (co), médula (me), filas de células corticales y medulares ramificadas (fcm). $100 \mathrm{x}$

D. antarctica. Transversal section showing early stage in conceptacle development, cortex (co), medulla (me), branching filaments of cortical and medullar cells (fcm). x 100 


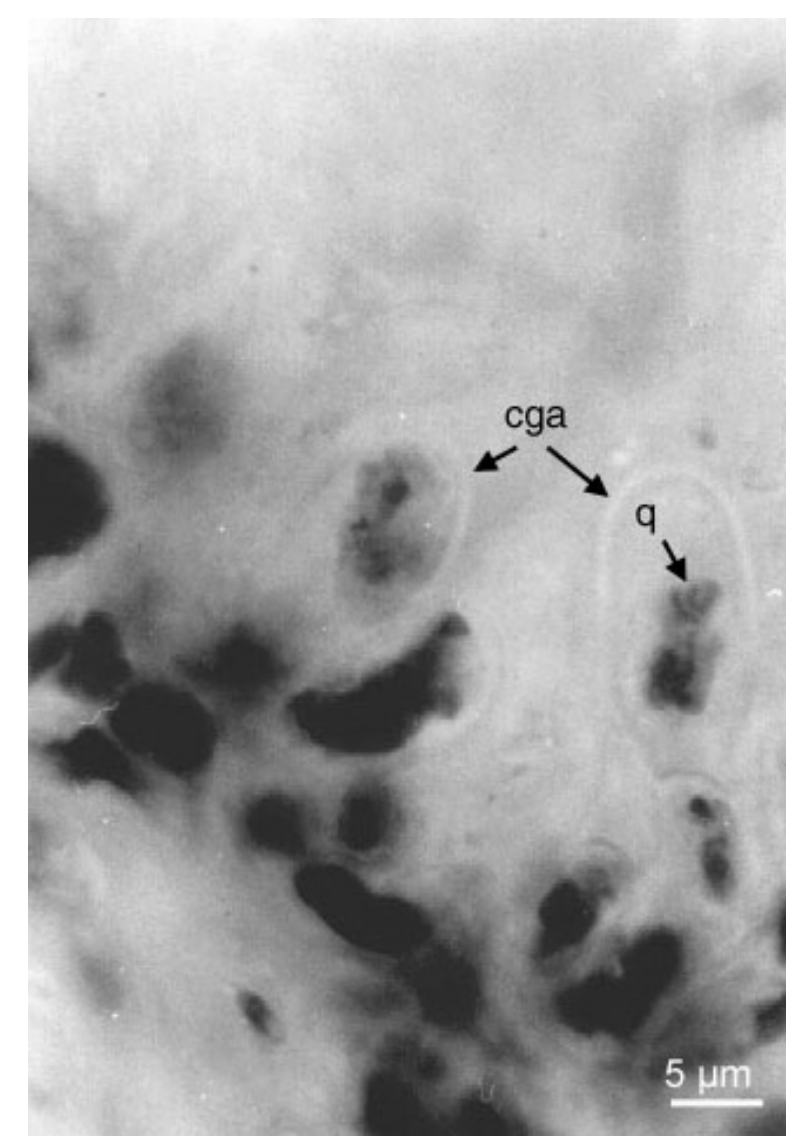

Figura 4

D. antarctica. Meiosis durante la profase I tardía, pares de cromosomas homólogos y quiasmas (q) son visibles en la célula germinativa del anteridio (cga). Reactivo de Shiff. 1000 x

D. antarctica. Meiosis during late profase I, homologous chromosomes pair and chiasmata (q) are visible in a germinative cell of an antheridium (cga).

Shiff reactive. $\mathrm{x} 1000$

Durante el inicio del período reproductivo, la observación de conceptáculos inmaduros no permitió distinguir sexo masculino y femenino. Posteriormente comenzaron a diferenciarse las células germinales de los anteridios y oogonios (ejemplares generalmente dioicos), desarrollándose en las células de las paredes o en las paráfisis simples o ramificadas de los conceptáculos, distinguiéndose éstas por la forma inicial ovoide, las cuales se alargaron progresivamente. De esta manera, en las paredes de los conceptáculos masculinos, fue posible observar diferentes estados de maduración de las células germinativas: con un núcleo durante la interfase, con dos y cuatro núcleos durante el transcurso de la meiosis I y II respectivamente $\mathrm{y}$ de ocho a sesenta y cuatro núcleos durante el transcurso de cuatro mitosis sucesivas, correspondiendo cada uno de ellos a los futuros anterozoides con nivel de ploidía $n=5-6$ (Figs.
4 y 5). Los anteridios con 64 anterozoides se presentaron envueltos por el endoquiton, túnica translúcida con un compartimento, a su vez protegida por una envoltura externa rígida y transparente, correspondiente al exoquiton (Fig. 6). Las paráfisis simples o ramificadas y los anteridios constituyeron ramilletes cubriendo la totalidad de las paredes de los conceptáculos (Figs. 7 y 8).

En las paredes de los conceptáculos femeninos fue posible observar diferentes estados de maduración de las células germinativas: con un núcleo durante la interfase, con dos y cuatro núcleos durante el transcurso de la meiosis I y II respectivamente seguida de una mitosis sin tabicación, dando origen a cuatro oosferas binucleadas (Fig. 9). Estas células se observaron envueltas por el endoquiton, túnica translúcida, cada una en un compartimento propio, ubicadas una en cada extremo y dos en el centro, a su vez rodeadas por un

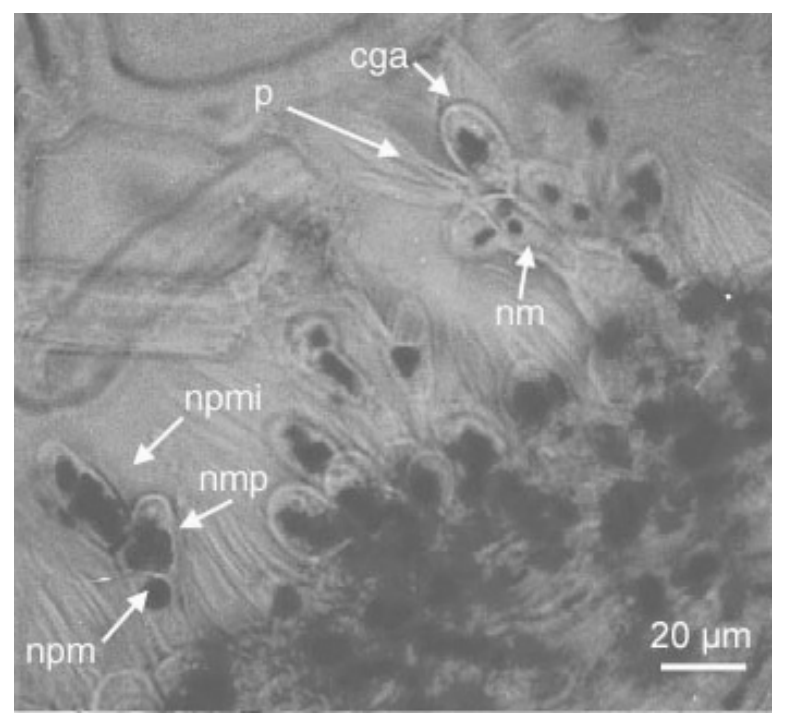

Figura 5

D. antarctica. Fronda dioica. Corte transversal de la pared de un conceptáculo, mostrando: paráfisis $(p)$, células germinales de los anteridios en paráfisis ramificadas (cga), núcleo pre meiótico $(\mathrm{npm})$, dos núcleos post meiosis I (nm) y cuatro núcleos post meiosis II (nmp), ocho núcleos post mitosis en un estado temprano del desarrollo de los anteridios (npmi). $400 \mathrm{x}$

D. antarctica. Dioecious frond. Transversal section through male conceptacle showing paraphyses (p), germinative cells (cga) on branching paraphyses, pre meiotic nuclei (npm), two nuclei post meiosis I (nm) and four nuclei post meiosis II (nmp), early stage of anteridial development showing eight post mitotic nuclei (npmi). x 400 


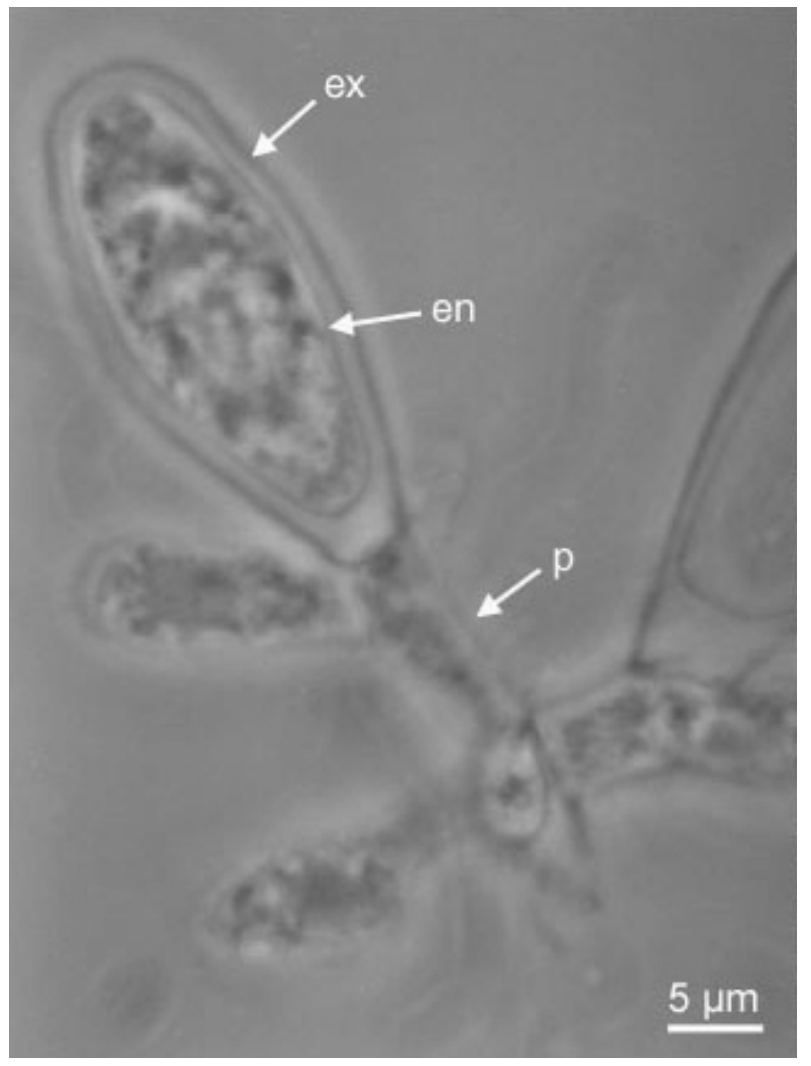

Figura 6

D. antarctica. Fronda dioica. Paráfisis ramificada (p) con anteridio maduro mostrando dos envolturas, endoquiton (en) y exoquiton (ex). $1000 \mathrm{x}$

D. antarctica. Dioecious frond. Branched paraphyse (p) showing mature antheridium within the inner endochite (en) and the outer exochite (ex). x 1000

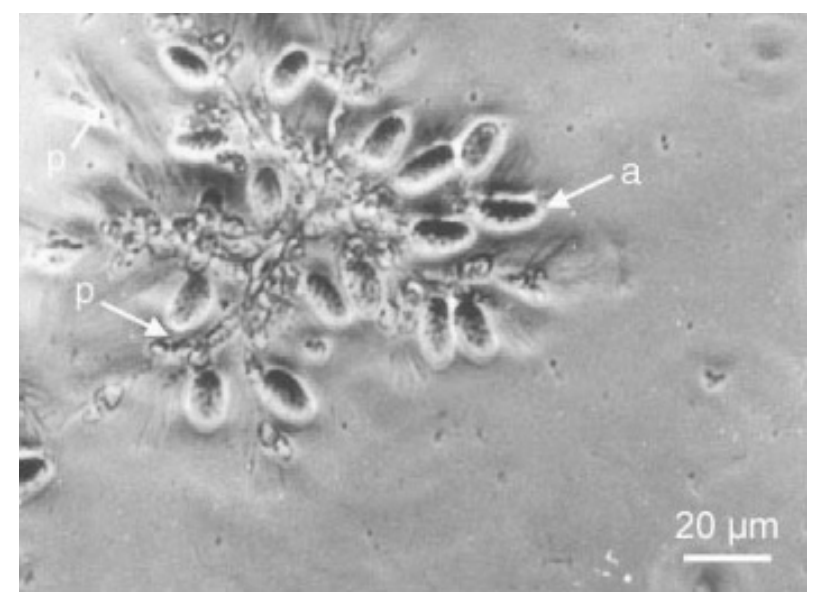

Figura 7

D. antarctica. Fronda dioica. Ramillete masculino con paráfisis (p) y anteridios (a). $200 \mathrm{x}$

D. antarctica. Dioecious frond. Male cluster of paraphyses (p) and antheridia (a). x 200

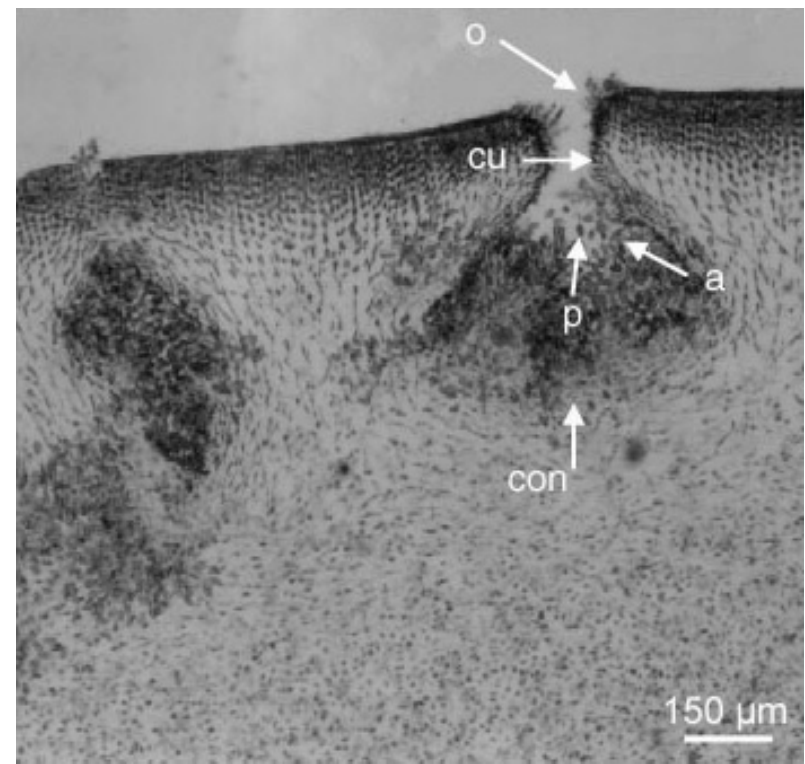

Figura 8

D. antarctica. Fronda dioica. Conceptáculo masculino (con) mostrando el ostíolo (o), cuello (cu), ramilletes con paráfisis (p) y anteridios (a). $40 \mathrm{x}$

D. antarctica. Dioecious frond. Male conceptacle (con) showing ostiole (o), gullet (cu), cluster of paraphyses (p) and antheridia (a). x 40

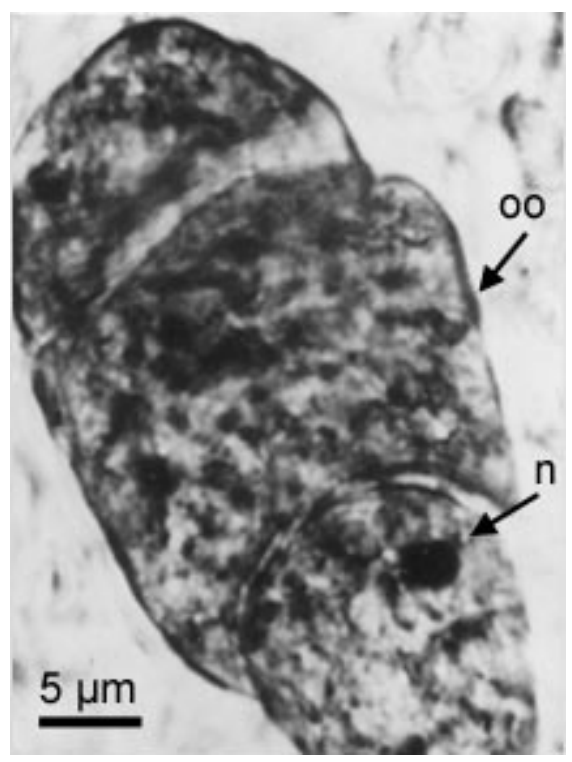

Figura 9

D. antarctica. Fronda dioica. Oogonio de cuatro oosferas (oo) binucleadas (n), mostrando tres de ellas en vista lateral. $1000 \mathrm{x}$

D. antarctica. Dioecious frond. Lateral view of tetrads of oospheres (oo) within the oogonium, nuclei (n). x 1000 


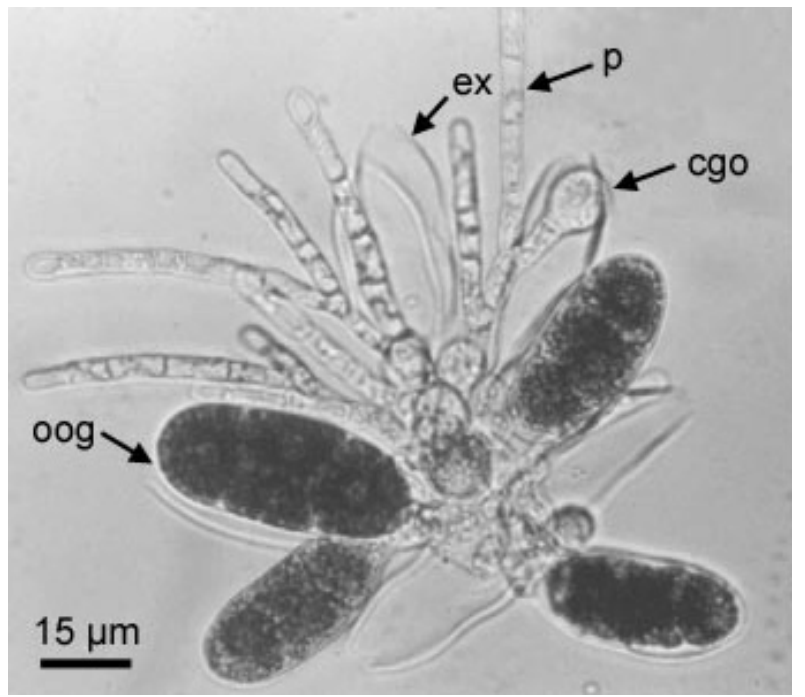

Figura 10

D. antarctica. Fronda dioica. Ramillete femenino con paráfisis (p), célula germinal del oogonio (cgo), oogonios de cuatro oosferas en vista frontal y lateral $(\mathrm{oog})$ y exoquiton vacío (ex). $400 \mathrm{x}$

D. antarctica. Dioecious frond. Female cluster of paraphyses (p), germinative cell of oogonia (cgo), lateral and frontal view of tetrads of oospheres within the oogonia (oog) and empty exochite (ex). x 400

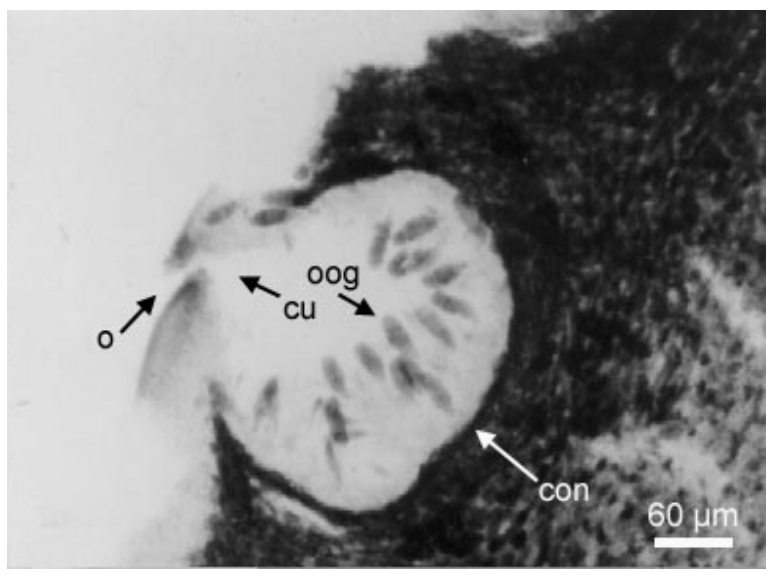

Figura 11

D. antarctica. Fronda dioica. Conceptáculo femenino (con), mostrando el ostíolo (o) cuello (cu) y oogonios (oog). $100 \mathrm{x}$

D. antarctica. Dioecious frond. Female conceptacle (con) showing ostiole (o), gullet (cu) and oogonia (oog). x 100

exoquiton único (Fig.10). Los oogonios y las paráfisis simples o ramificadas constituyeron ramilletes cubriendo la totalidad de las paredes de los conceptáculos (Fig. 11).

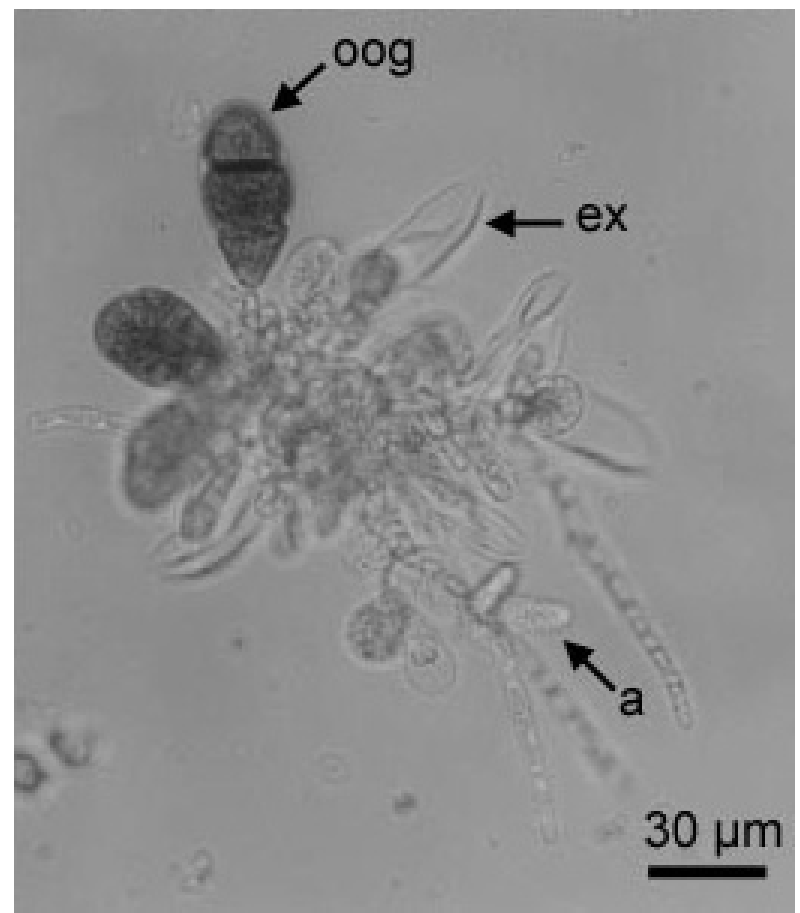

Figura 12

D. antarctica. Fronda monoica. Ramillete de oogonios (oog), anteridios (a) y exoquiton vacíos (ex). $200 \mathrm{x}$

D. antarctica. Monoecious frond. Cluster of oogonia (oog), antheridia (a) and empty exochiton (ex). x 200

Los cortes transversales de los trozos demostraron que el piso de los conceptáculos de los talos dioicos presentó anteridios u oogonios y células germinativas en diferentes estados de maduración, en ramilletes con paráfisis estériles (Figs. 8, 10 y 11).

Durante todo el período de estudio, entre 100 especímenes, sólo se encontró un ejemplar monoico con conceptáculos portando a la vez anteridios y oogonios (Fig. 12).

\section{Fenología de los estados vegetativos y reproductivos en conceptáculos de ejemplares intermareales $(>50 \mathrm{~cm})$}

El estudio de cortes histológicos de un total de 100 trozos de ejemplares intermareales, recolectados entre los meses de marzo a octubre de 1997 y febrero y marzo de 1998 indicó la presencia de 98\% y 2\% de ejemplares con uno y dos estratos de conceptáculos respectivamente.

De acuerdo a los estados de desarrollo descritos en la ontogenia de los conceptáculos, los diferentes estados vegetativos y reproductivos de $D$. antarctica, obtenidos a partir de los cortes histológicos de explantes 
recolectados durante 1997 y 1998, fueron determinados de acuerdo a la siguiente nomenclatura y correspondiente caracterización:

- estado vegetativo (0V), ausencia de diferenciación celular (Fig. 13) o diferenciación celular inicial para la formación de conceptáculos entre la subcorteza y la médula

- estado reproductivo inmaduro (1RI), presencia y desarrollo gradual de diferenciación celular entre la corteza y la médula para la formación de conceptáculos; cuando está presente el lumen, éste es pequeño e irregular con desarrollo inicial de las células germinativas de los anteridios y oogonios. No es posible determinar sexo. Las paráfisis son delgadas y cortas. (Fig 14)

- estado reproductivo inmaduro (2RI), conceptáculo de forma ovalada con piso cóncavo ó plano, diferenciación asincrónica de anteridios y oogonios, 8-16 y 1 células respectivamente, hifas largas simples y ramificadas (Fig. 15 )

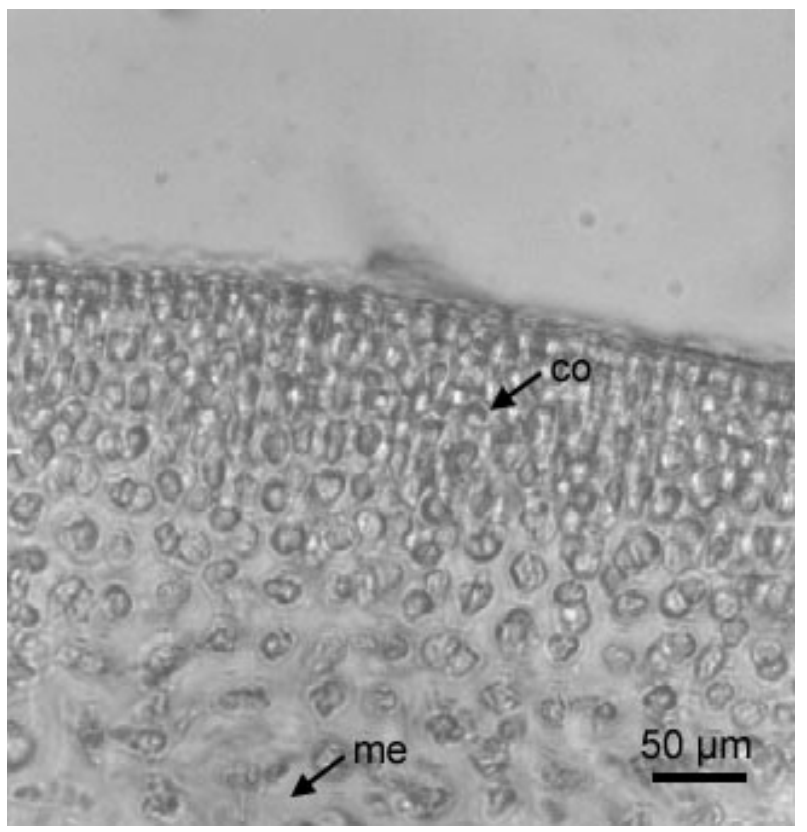

Figura 13

D. antarctica. Corte transversal de una fronda vegetativa $(0 \mathrm{~V})$, mostrando corteza (co) y parte de la médula (me). $400 x$

D. antarctica. Transversal section of a vegetative frond $(0 \mathrm{~V})$ showing cortex (co) and medullar cells (me). x 400

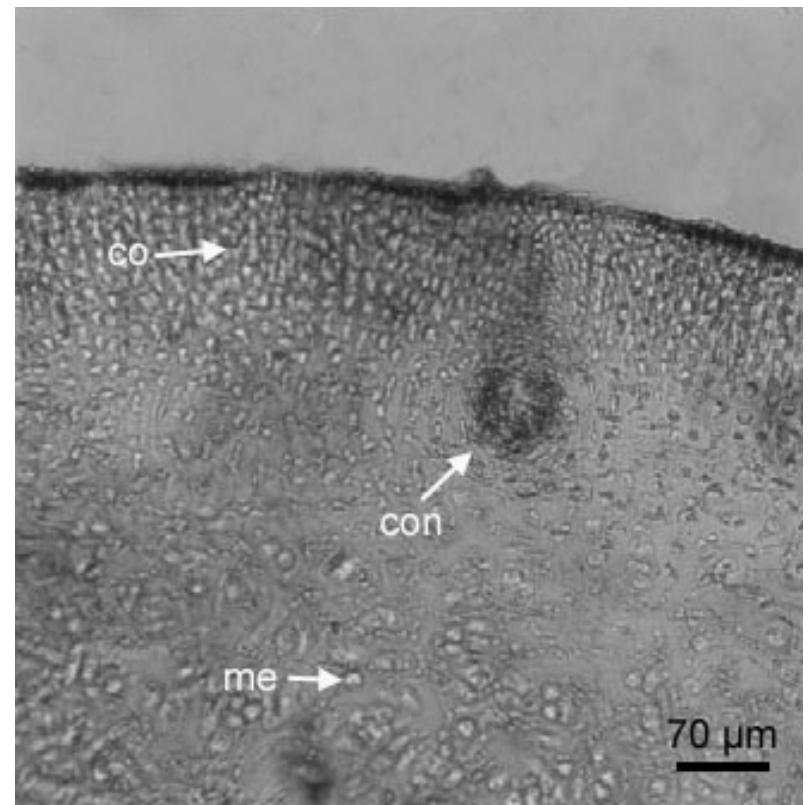

Figura 14

D. antarctica. Conceptáculo inmaduro (con) de una fronda reproductiva inmadura (1RI), mostrando corteza (co), médula (me) y lumen incipiente (l). $100 \mathrm{x}$

D. antarctica. Inmature conceptacle (con) of a reproductive frond (1RI), showing cortex (co), medulla (me) and initial lumen (1). x 100

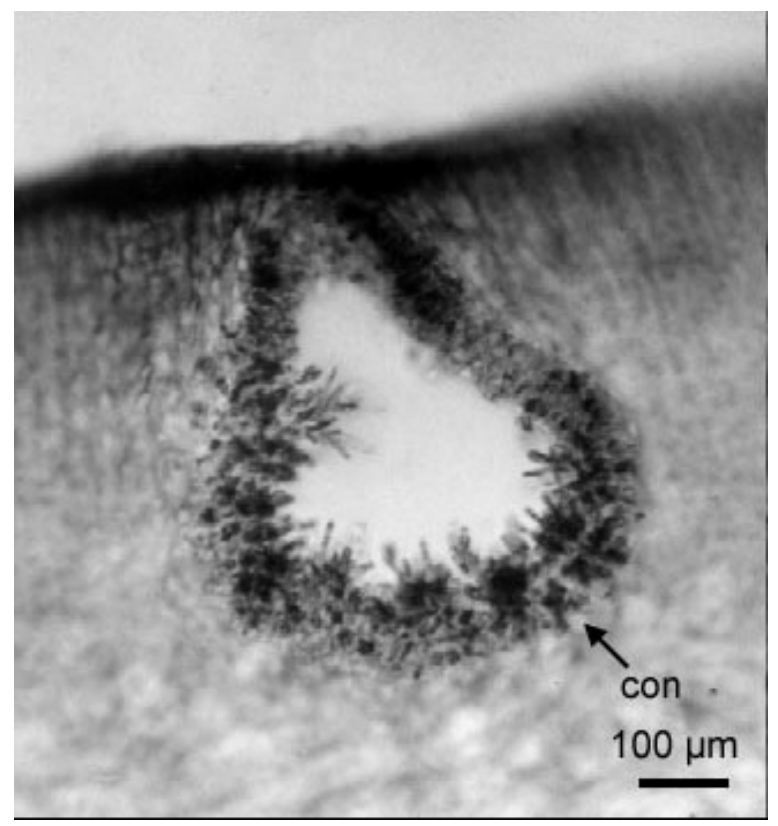

Figura 15

D. antarctica. Conceptáculo masculino (con) de una fronda reproductiva inmadura $(2 \mathrm{RI})$, piso cóncavo, lumen desarrollado (l). $200 \mathrm{x}$

D. antarctica. Male conceptacle (con) of an inmature reproductive frond (2RI), concave floor, developed lumen (1). x 200 
- estado reproductivo maduro (3RM), conceptáculo completamente desarrollado de forma ovalada con piso cóncavo o plano. Aunque la gametogénesis no es sincrónica y se encuentran todas las etapas de maduración, los anteridios y oogonios maduros presentan 64 y 4 células respectivamente. Ambas estructuras reproductivas están aptas para liberar anterozoides y oosferas al medio. El cuello y poro de salida del conceptáculo u ostíolo en esta etapa son conspicuos, las paráfisis son simples, largas y/o ramificadas (Figs. 16a y 16b)

- estado reproductivo senescente (4RS), conceptáculo con escasa o nula presencia de oogonios y anteridios, a veces en proceso de reabsorción, paráfisis también escasas e irregulares, exoquiton vacíos (Fig. 17).

Los estados reproductivos predominaron durante los meses de recolección, marzo a octubre de 1997, fluctuando entre un $80-100 \%$, excepto en el mes de abril con un descenso a $60 \%$ en coincidencia con un aumento a $40 \%$ de estado vegetativos. A diferencia de estos resultados en febrero y marzo de 1998, aumentan los estados vegetativos con valores de 60 a $80 \%$ presentando los porcentajes más bajos de estados reproductivos con un $40 \%$ y $20 \%$ respectivamente (Fig. 18).

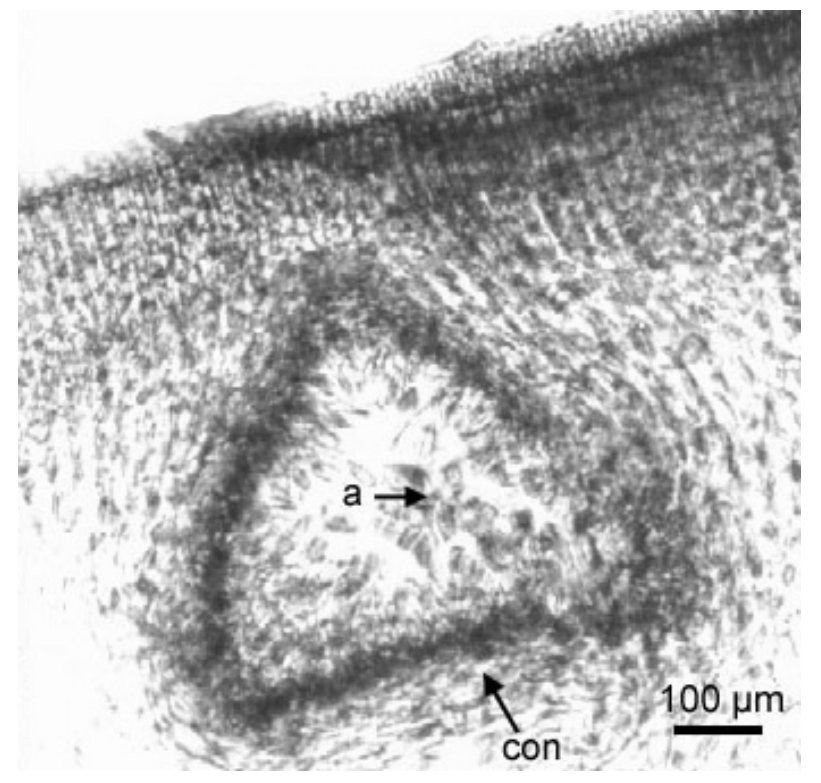

Figura 16a

D. antarctica. Fronda dioica. Conceptáculo masculino (con) de una fronda reproductiva madura (3RM), piso plano, mostrando anteridios (a). $200 \mathrm{x}$

D. antarctica. Dioecious frond. Male mature conceptacle (con) of a reproductive plant (3RM), plain floor, showing antheridia (a). x 200

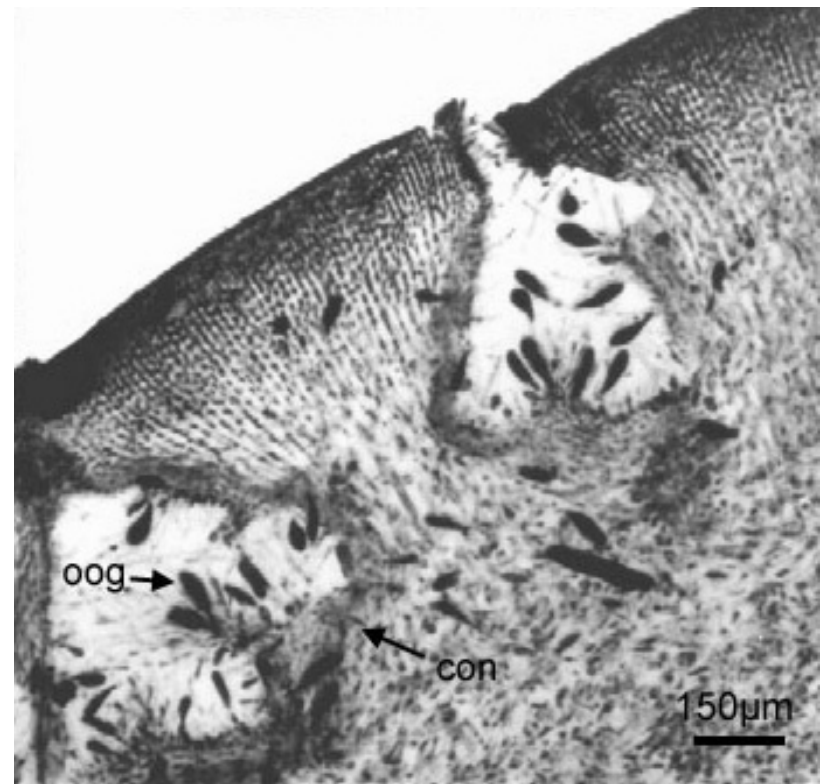

Figura 16b

D. antarctica. Fronda dioica. Conceptáculo femenino (con) de un ejemplar reproductivo maduro (3RM), piso cóncavo, mostrando oogonios (oog). $40 \mathrm{x}$

D. antarctica. Dioecious frond. Female mature conceptacle (con)of a reproductive plant (3RM), concave floor showing oogonia (oog). x 40

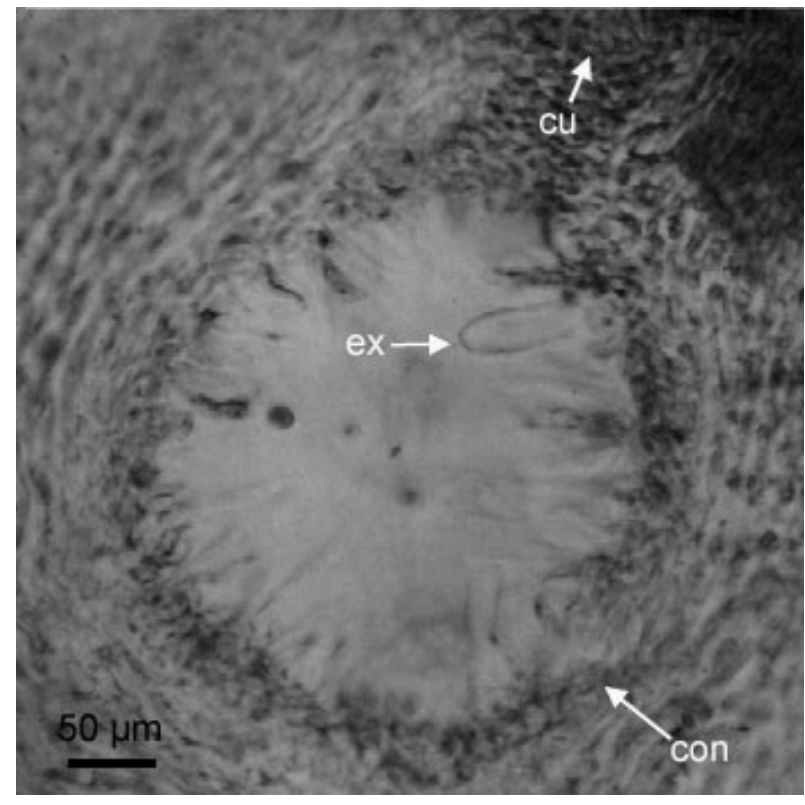

Figura 17

D. antarctica. Conceptáculo (con) de una fronda reproductiva senescente (4RS), exoquiton vacíos (ex) y cuello ocluido (cu) $400 \mathrm{x}$

D. antarctica. Senescent conceptacle (con) of a reproductive frond (4RS), empty exochite (ex) and gullet ocluded (cu). x 400 


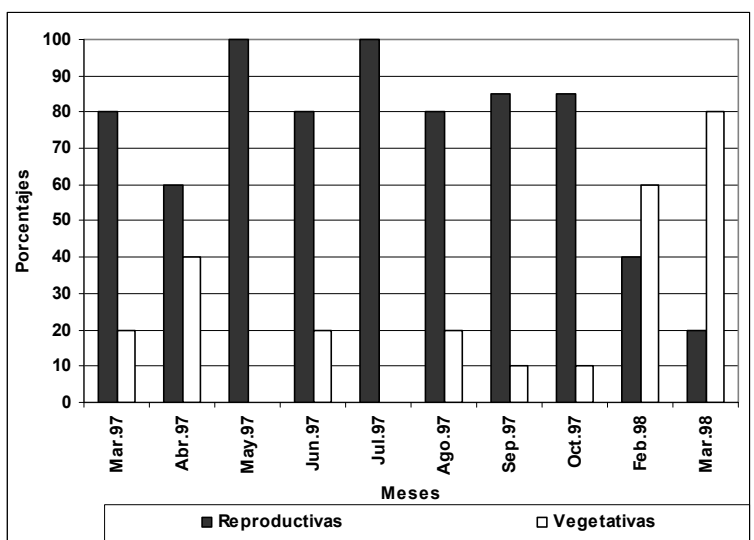

Figura 18

D. antarctica. Caleta Montemar, frondas intermareales 1997/98. Porcentajes de distribución mensuales de ejemplares vegetativos y reproductivos

D. antarctica. Montemar cove, intertidal fronds 1997/98.

Percentages of monthly distribution of vegetative and reproductive plants

La distribución temporal de estados vegetativos y reproductivos de $D$. antarctica, presentó las siguientes combinaciones de estados de maduración (Fig. 19):

- estados vegetativos $(0 \mathrm{~V})$, en el inicio de la maduración (1RI), en maduración (2RI) y maduros (3RM) desde marzo a julio (otoño, invierno), exceptuando abril y mayo con estados (1RI) y $(0 \mathrm{~V})$ respectivamente no detectados

- estados vegetativos $(0 \mathrm{~V})$ y reproductivos maduros (3RM) en agosto (invierno)

- estados vegetativos $(0 \mathrm{~V})$, en maduración (2RI) y maduros (3RM) en septiembre (invierno)

- estados vegetativos (0V), maduros (3RM) y senecentes (4RS) en octubre (primavera)

- estados vegetativos (0V) y senescentes (4RS) en febrero y marzo (verano).

$\mathrm{Al}$ analizar los estados vegetativos y reproductivos de los ejemplares, éstos no fueron independientes del mes de muestreo, existieron diferencias significativas entre el número de ejemplares reproductivos $\mathrm{y}$ vegetativos en los meses de mayo y julio (otoño e invierno) (Test $\mathrm{G}, \mathrm{P}<0,01$ ). $\mathrm{Al}$ analizar el conjunto de meses de muestreo, se encontró un número mayor de ejemplares reproductivos que vegetativos (Test chicuadrado, $\mathrm{P}<0,01$ ), sin embargo esta tendencia no fue uniforme, puesto que en los muestreos febrero/marzo 1998, se observaron mayores porcentajes de estados vegetativos $(60-80 \%)$ que reproductivos $(20-40 \%)$, aunque estas diferencias no fueron significativas (Test chi- cuadrado, $\mathrm{P}>0,01$ ).

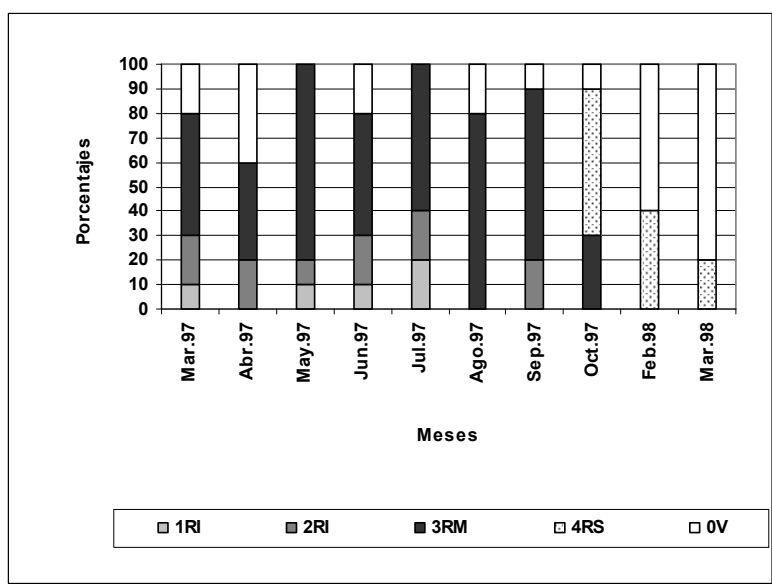

Figura 19

D. antarctica. Caleta Montemar, frondas intermareales 1997/98. Porcentajes de distribución mensuales de ejemplares según estados vegetativo y reproductivos D. antarctica. Montemar cove, intertidal fronds 1997/98. Percentages of monthly distribution of vegetative and reproductive stages

En el análisis de la distribución temporal de los estados reproductivos de $D$. antarctica del período de estudio, existió una predominancia significativa de estados maduros ( $3 \mathrm{RM})$ en relación al estado vegetativo $(0 \mathrm{~V})$ y reproductivos no maduros (1RI y $2 \mathrm{RI})$ en los meses de mayo/97, agosto/97 y septiembre/97 (test chicuadrado y test $\mathrm{G}, \mathrm{P}<0,01)$. Entre los diferentes meses de recolección los estados reproductivos analizados por separado se distribuyeron en forma homogénea existiendo diferencias significativas sólo para el estado reproductivo maduro (4RS) presente en los meses de febrero/98 y marzo/98 (test chi-cuadrado y $\mathrm{G} ; \mathrm{P}<0,01$ ).

En este trabajo la distribución temporal de los ejemplares intermareales de $D$. antarctica en caleta Montemar, presentó estados vegetativo y reproductivos (Figs. 18 y 19) y un flujo de maduración con dos períodos, reproductivo y vegetativo (Tabla 1). El período reproductivo con una secuencia inicial creciente de estados vegetativos $(0 \mathrm{~V})$ a reproductivos en las que es posible encontrar los dos estados inmaduros y el maduro (1RI, 2RI, 3RM), desde marzo/97 hasta julio/97; seguido por el inicio del cese reproductivo en que los ejemplares vegetativos $(0 \mathrm{~V})$ detienen su flujo de maduración, hecho que se constata por la ausencia de estados reproductivos inmaduros (1RI) y presencia de ejemplares en maduración y maduros (2RI y $3 R M)$ en agosto/97 y septiembre/97; finalmente el término del período reproductivo de maduración con estados maduros y senescentes (3RM y 4RS) en el mes de octubre/97. Parte de los ejemplares vegetativos $(0 \mathrm{~V})$ 
del período reproductivo marzo/97 a octubre/97 no siguen el flujo de maduración respectivo y continúan por una vía vegetativa probable de crecimiento (Tabla $1)$.

El período vegetativo siguiente presentó ejemplares vegetativos (0V) y senescentes (4RS) ambos en crecimiento en los meses de verano febrero/98 y marzo/98 (Fig 19, Tabla 1).

\section{Estados vegetativos $y$ reproductivos de conceptáculos en ejemplares varados $(>50 \mathrm{~cm})$}

La revisión de cortes histológicos de 101 ejemplares, varados en una braveza de mar de julio 2001, demostraron la presencia de ejemplares en todos los estados, vegetativo (0V-9\%) y reproductivos (1RI20\%), (2RI-65\%), (3RM-4\%), incluso senescentes (4RS-2\%). El estado reproductivo en desarrollo (2RI) fue el más representado, seguido por el estado inmaduro (1RI).

En 92 especímenes se observaron conceptáculos en estratos, en una $(61 \%)$, dos $(36 \%)$ y tres $(3 \%)$ capas (Fig. 20).

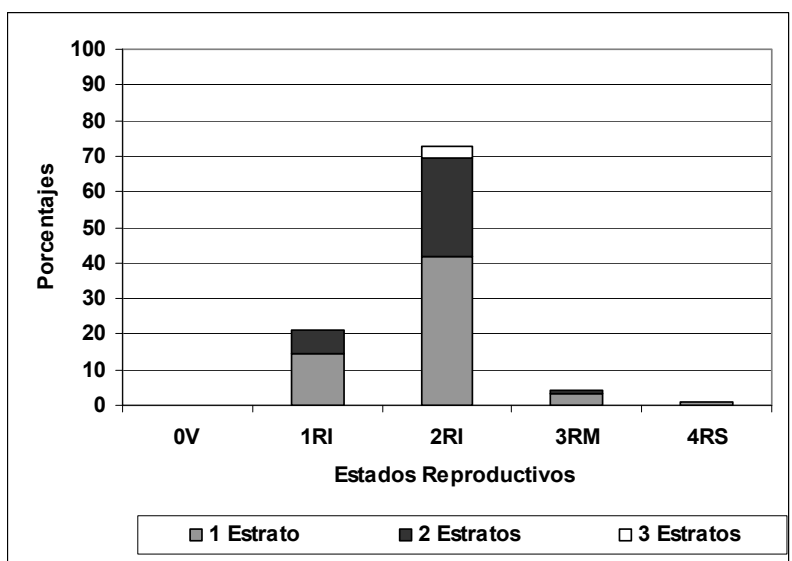

Figura 20

D. antarctica. Caleta Montemar frondas varadas, julio 2001. Porcentajes de distribución de estratos de conceptáculos según estados vegetativo y reproductivos

D. antarctica. Montemar cove, drift fronds, July 2001. Percentages distribution of conceptacle layers according to vegetative and reproductive stages

\section{Tabla 1}

D. antarctica. Períodos reproductivo y vegetativo. Flujo de maduración del estado vegetativo y de los reproductivos D. antarctica. Reproductive and vegetative periods. Maturity flux of vegetative and reproductive stages

\begin{tabular}{|c|c|c|}
\hline \multicolumn{3}{|l|}{$\downarrow \downarrow$} \\
\hline $\mathrm{OV} \rightarrow 1 \mathrm{RI} \rightarrow 2 \mathrm{RI} \rightarrow 3 \mathrm{RM}$ & Período reproductivo & marzo/97 - julio/97 \\
\hline$\downarrow \quad \downarrow$ & & \\
\hline $2 \mathrm{RI} \rightarrow 3 \mathrm{RM}$ & Inicio cese reproductivo & agosto/97 - septiembre/97 \\
\hline$\downarrow$ & & \\
\hline $3 R M \rightarrow 4 R S$ & Término de la maduración & octubre/97 \\
\hline$\downarrow$ & & \\
\hline $\mathrm{OV} \rightarrow \rightarrow \leftarrow \leftarrow \leftarrow \leftarrow \leftarrow \leftarrow \leftarrow 4 \mathrm{RS}$ & Período vegetativo & febrero/98 - marzo/98 \\
\hline$\downarrow \downarrow$ & & \\
\hline $\mathrm{OV}=$ estado vegetativo & $\mathrm{RM}=$ estado reproductivo mad & \\
\hline $1 \mathrm{RI}=$ estado reproductivo inmaduro & $\mathrm{RS}=$ estado reproductivo sene & cente \\
\hline $2 \mathrm{RI}=$ estado reproductivo inmaduro & $\rightarrow=$ sentido del flujo & \\
\hline
\end{tabular}

\section{Liberación de gametos en ejemplares reproductivos}

En frondas masculinas inducidas por efecto de desecación y humectación a liberar los anterozoides, éstos no irrumpieron aislados sino dentro de los anteridios, saliendo abruptamente entre las paráfisis y por el ostíolo del conceptáculo. Los anteridios abandonaron el exoquiton que se rompió en su polo anterior o en todo su largo quedando vacío, unido a las células del piso o a las paráfisis ramificadas del conceptáculo (Fig. 21). Una vez libres, se hidrató el endoquiton, pudiéndose apreciar en el interior del anteridio movimientos de los flagelos de los anterozoides, tratando de salir al exterior por la abertura en uno de los extremos del endoquiton (Fig. 22). Los anterozoides libres presentaron forma reniforme u ovoide aguzada en uno de los extremos y su tamaño alcanzó $3 \mu \mathrm{m}$ de longitud, distinguiendose lateralmente dos flagelos, uno corto de 5,0 $\mu \mathrm{m}$ y otro largo de aproximadamente 10,5 $\mu \mathrm{m}$ (Fig. 23). La forma de nadar observada fue siempre muy lenta, impulsada por movimientos ondulantes de este último. 


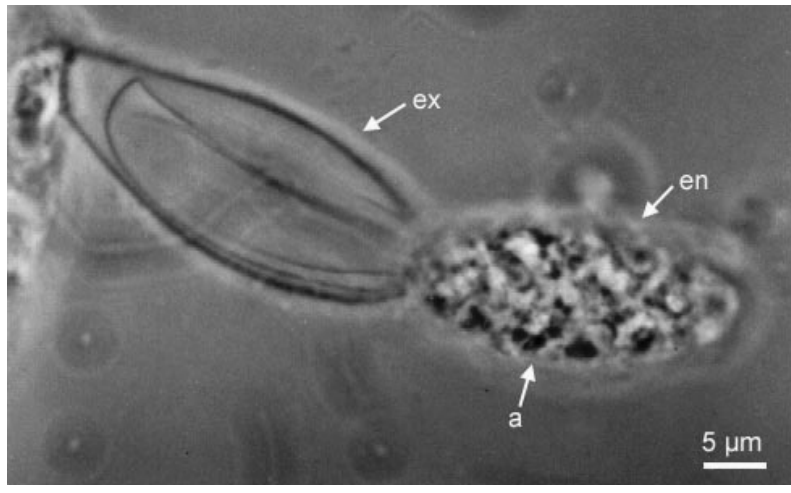

Figura 21

D. antarctica. Liberación de un anteridio (a) por rompimiento del exoquiton (ex). $1000 \mathrm{x}$

D. antarctica. Release of antheridium (a) by rupture of the exochite (ex). x 1000

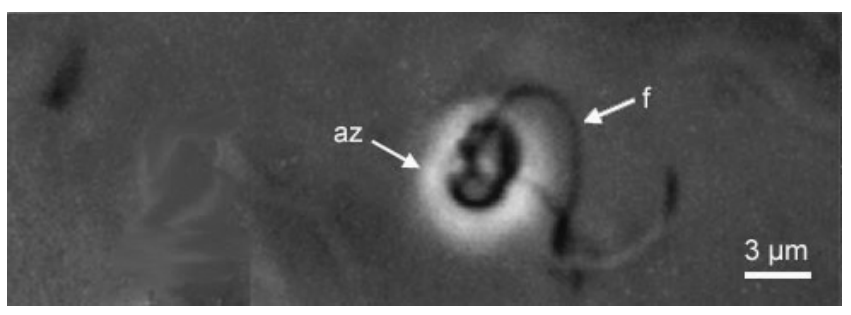

Figura 23

D. antarctica. Anterozoide biflagelado (az), con flagelo anterior más corto (f). $1000 \mathrm{x}$

D. antarctica. Biflagellate antherozoid (az), with shorter anterior flagellum (f). x 1000

En frondas femeninas maduras inducidas por efecto de desecación y humectación a liberar los oogonios, éstos irrumpieron abruptamente saliendo entre las paráfisis y por el ostíolo del conceptáculo, abandonando el exoquiton que se rompió en su polo anterior o en todo su largo quedando vacío, unido a las células del piso o a las paráfisis simples o ramificadas del conceptáculo (Fig. 10). Los oogonios una vez libres, hidrataron el endoquiton, pudiéndose apreciar movimientos de los cloroplastos en el citoplasma de las oosferas que salen al exterior, por la propia abertura de cada uno de los cuatro compartimentos del endoquiton. La salida de las oosferas se produjo a veces abruptamente $\mathrm{y}$ en ocasiones lentamente (aprox. $3 \mathrm{~min}$ ), extruyendo en este último caso, a través de un poro de aproximadamente 5 $\mu \mathrm{m}$ de diámetro, simultánea o secuencialmente desde todos los compartimentos del endoquiton (Figs. $24 \mathrm{y}$ 25). Una vez libres, las oosferas adquirieron forma esférica distinguiéndose al menos tres tamaños en el rango entre los 16 a $36 \mu \mathrm{m}$ de diámetro; presentaron movimientos lentos y giratorios sobre sí mismas y se observaron cubiertas por un delgado periplasto (Fig. 26).

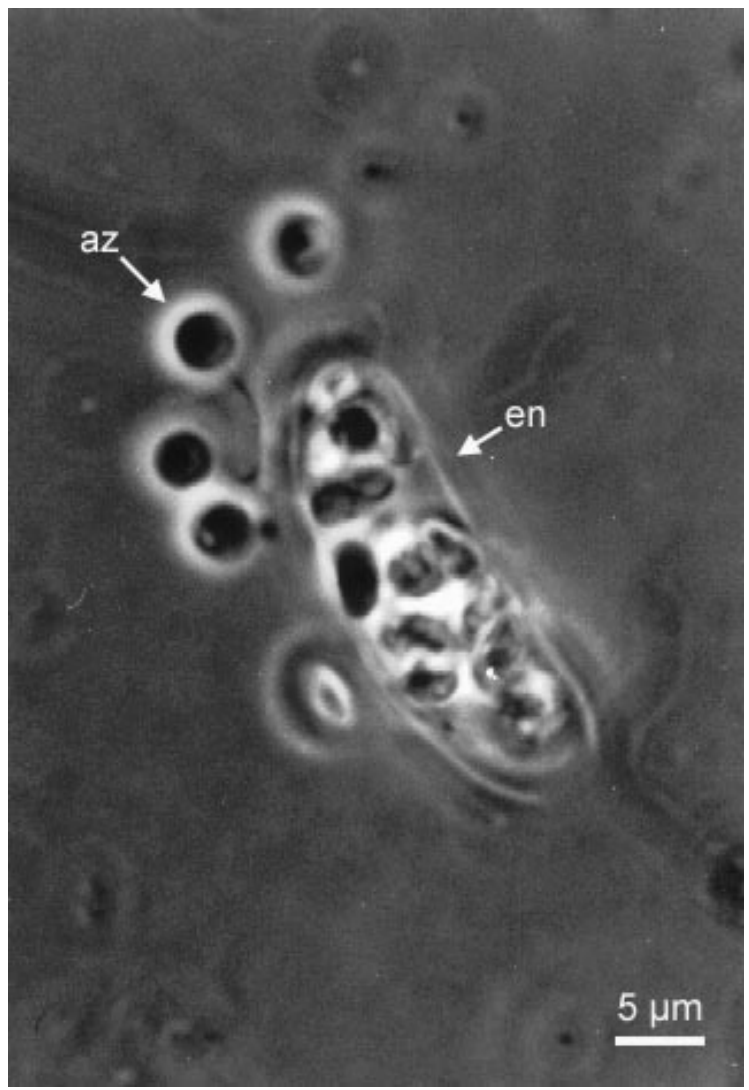

Figura 22

D. antarctica. Liberación de anterozoides (az) por rompimiento de un extremo del endoquiton (en). $1000 \mathrm{x}$

D. antarctica. Release of antherozoids (az) by rupture of the endochite (en). x 1000

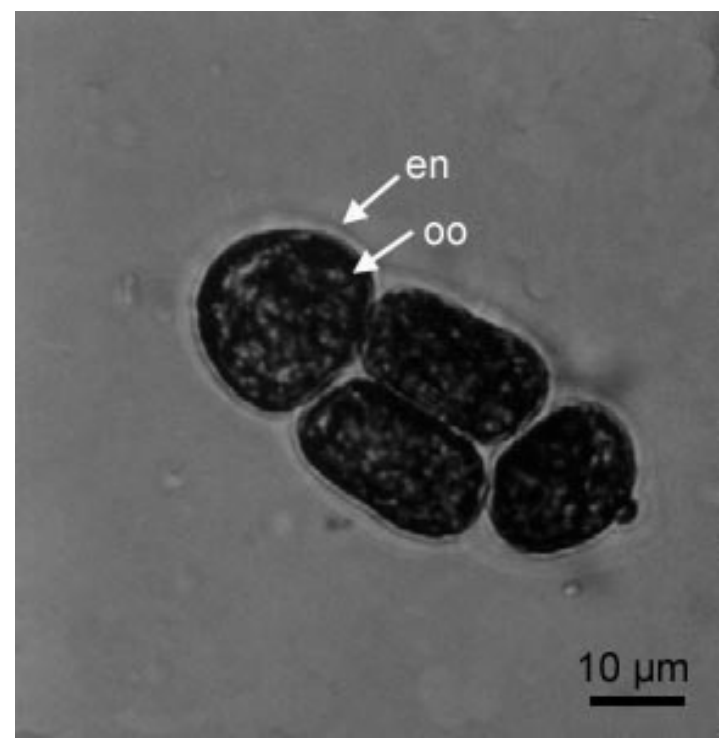

Figura 24

D. antarctica. Oogonio libre con cuatro oosferas (oo), envueltas por el endoquiton (en). $400 \mathrm{x}$

D. antarctica. Free oogonium with four oospheres (oo), wraped by endochite (en). x 400 


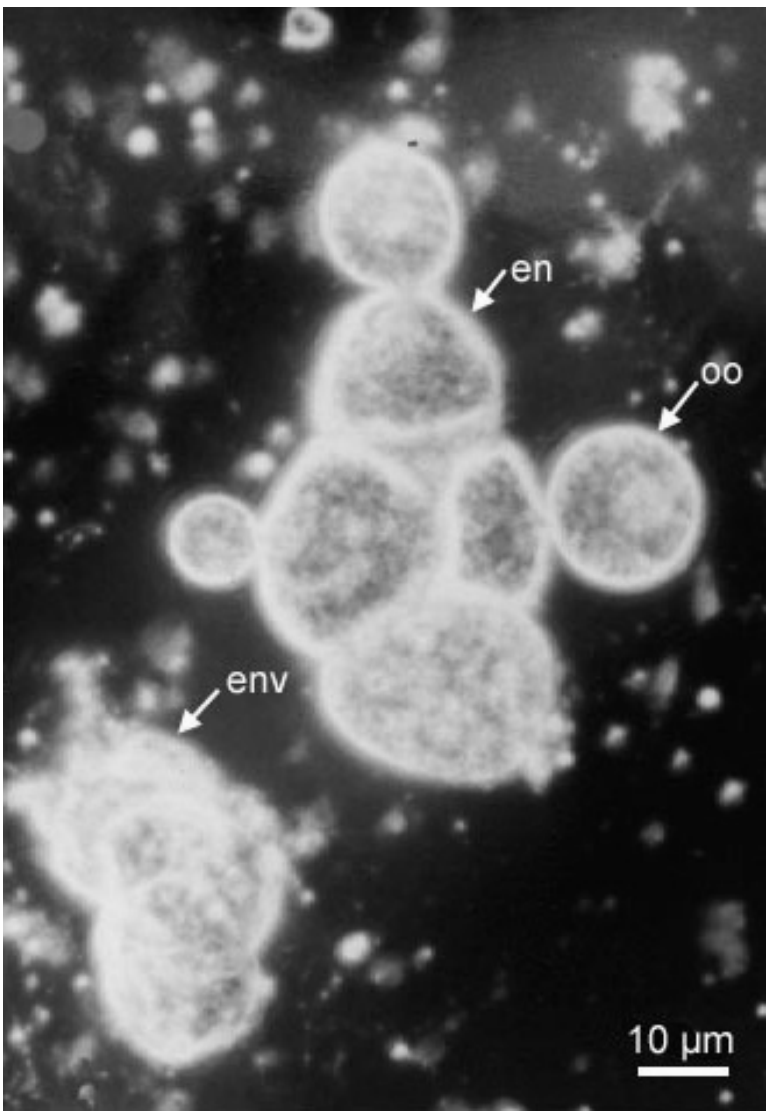

Figura 25

D. antarctica. Extrusión simultánea de oosferas (oo) desde cada compartimento del endoquiton (en) de un oogonio, endoquiton vacío de un oogonio (env). $400 \mathrm{x}$

D. antarctica. Simultaneous extrusion of oospheres (oo) from each compartment of an oogonium endochite (en), empty oogonium endochite (env). x 400

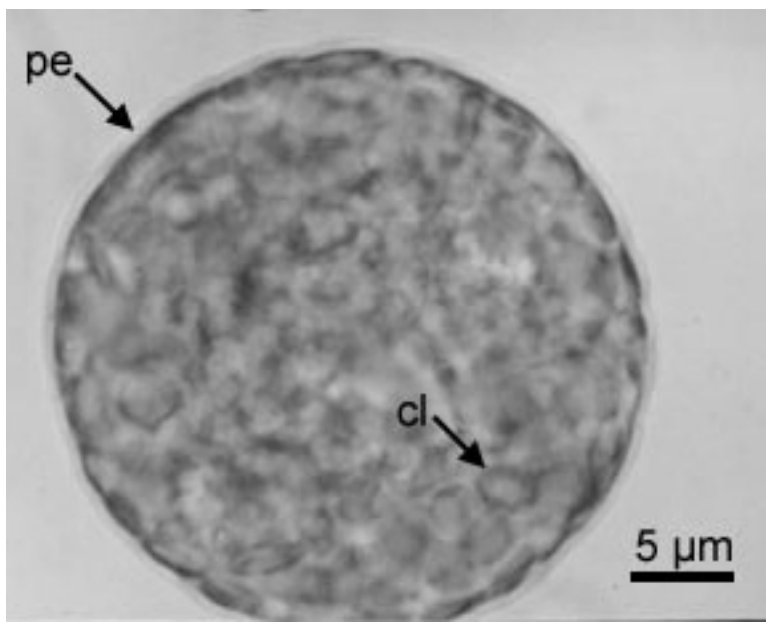

Figura 26

D. antarctica. Oosfera libre mostrando el periplasto (pe) y cloroplastos discoidales (cl). $1000 \mathrm{x}$

D. antarctica. Free oosphere showing periplast (pe) and discoidal cloroplasts (cl). x 1000

\section{Fertilización}

La fecundación inducida en una suspensión de oosferas y anterozoides, posibilitó el acercamiento de estos últimos a las oosferas mediante movimientos lentos de su flagelo largo. Una vez en contacto con el delgado periplasto de la oosfera, el anterozoide se acomodó dentro de un mismo punto, efectuando movimientos de tanteo con el extremo del flagelo más corto, hasta desaparecer sumergido en capas concéntricas de material mucilaginoso exudado por la pared de la oosfera. Este halo de fecundación, cuya síntesis es instantánea y evidente, inmediatamente después de ocurrida la fecundación, da origen al cigoto (Fig. 27). Este último, a diferencia de las oosferas no fecundadas, presentó dos zonas claras ("ojos") atribuíbles a los núcleos masculino y femenino (Fig. 28).

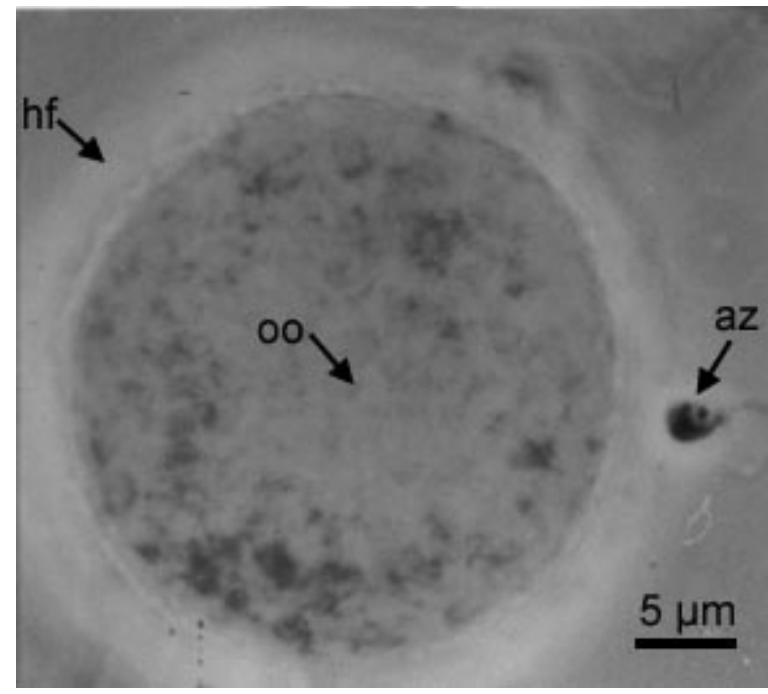

Figura 27

D. antarctica. Fecundación mostrando oosfera (oo), halo de fecundación (hf) y anterozoide (az). $1000 \mathrm{x}$

D. antarctica. Fertilization showing oosfera (oo), membrane of fertilization (hf), and antherozoid (az). x 1000

\section{Embriogénesis}

Doce horas después fue posible observar el desarrollo de dos patrones de germinación de embriones distinguibles por su polaridad simétrica y asimétrica. Estos últimos, a las $24 \mathrm{~h}$ de desarrollo, presentaron un tabique transversal que indica la ocurrencia de la primera mitosis y la consecuente diferenciación del embrión en las células iniciales de la fronda y el rizoide (Figs. 29 y 30). La primera, de mayor tamaño $(40 \mu \mathrm{m})$, muy pigmentada, con una notoria rotura en la pared celular de su porción basal, dando paso al crecimiento de la célula inicial del rizoide, de tamaño pequeño 


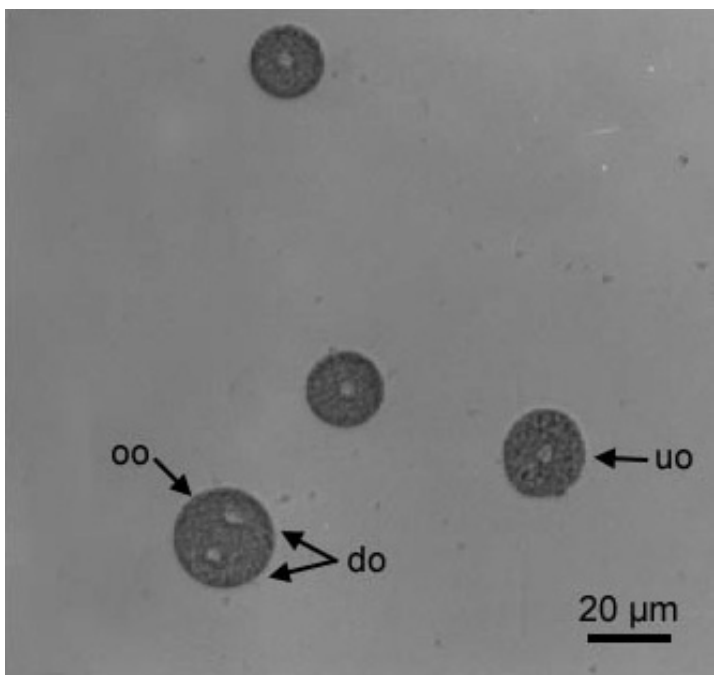

Figura 28

D. antarctica. Oosfera (oo) fertilizada (“dos ojos") (do) y oosfera no fertilizada ("un ojo") (uo). $200 \mathrm{x}$

D. antarctica. Fertilized oosphere (oo) ("two eyes") (do) and unfertilized oosphere ("one eye") (uo). x 200

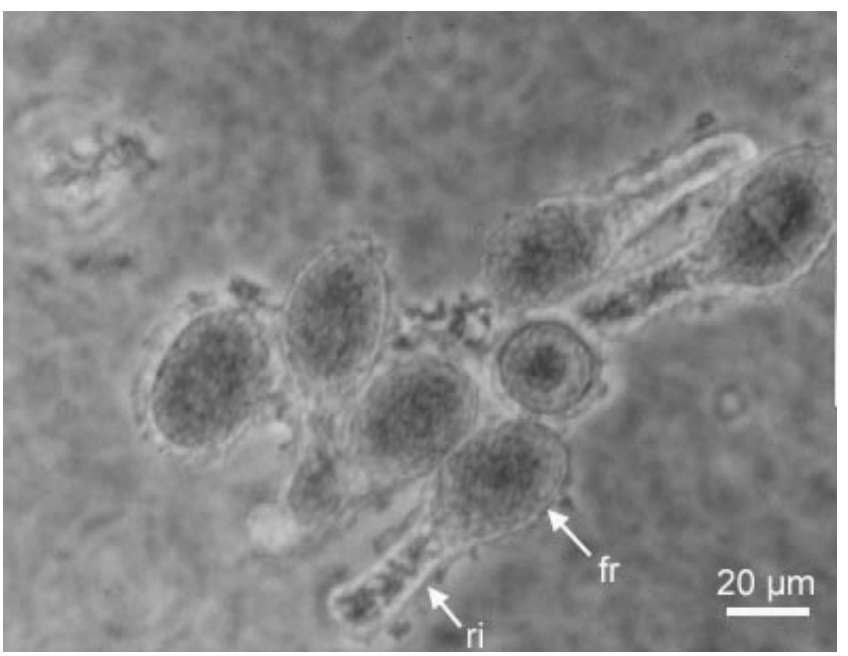

Figura 30

D. antarctica. Embriones de $\mathbf{7 2}$ h mostrando las células de la fronda (fr) y del rizoide (ri). $200 \mathrm{x}$

D. antarctica. Embryos $72 \mathrm{~h}$ after fertilization showing frond cells (fr) and rhizoid cells (ri). x 200

$(15 \mu \mathrm{m})$ y poco pigmentada. Ambas células se dividen varias veces transversalmente, las de la fronda también en un plano perpendicular al primero originando una plántula multicelular (Fig. 31). Una cubierta de mucílago es notoria al exterior de la pared celular de las células rizoidales, para permitir el asentamiento de las plántulas. Una cubierta rígida en forma de gorro

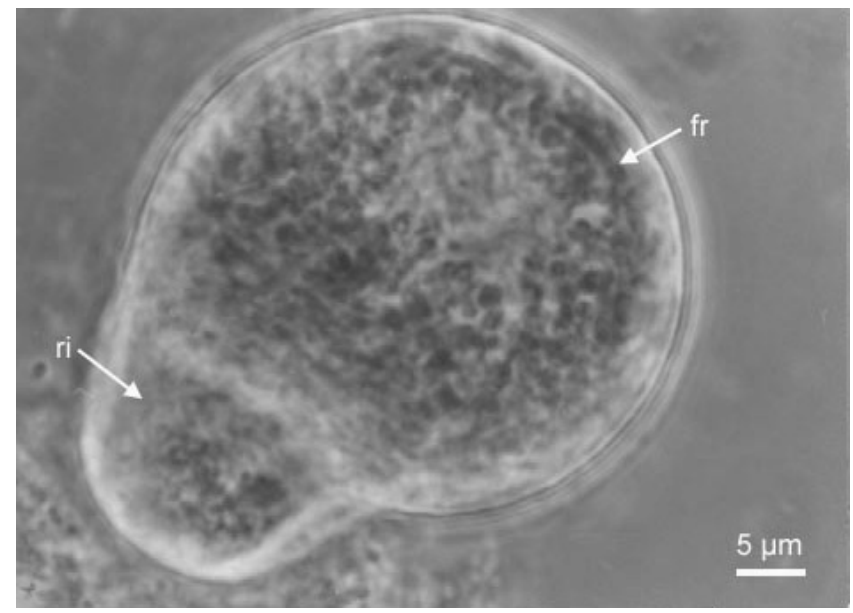

Figura 29

D. antarctica. Embrión de 24 h mostrando la célula de la fronda (fr) $\mathrm{y}$ del rizoide (ri). $1000 \mathrm{x}$

D. antarctica. Embryo $24 \mathrm{~h}$ after fertilization showing frond cell (fr) and rhizoid cell (ri). x 1000

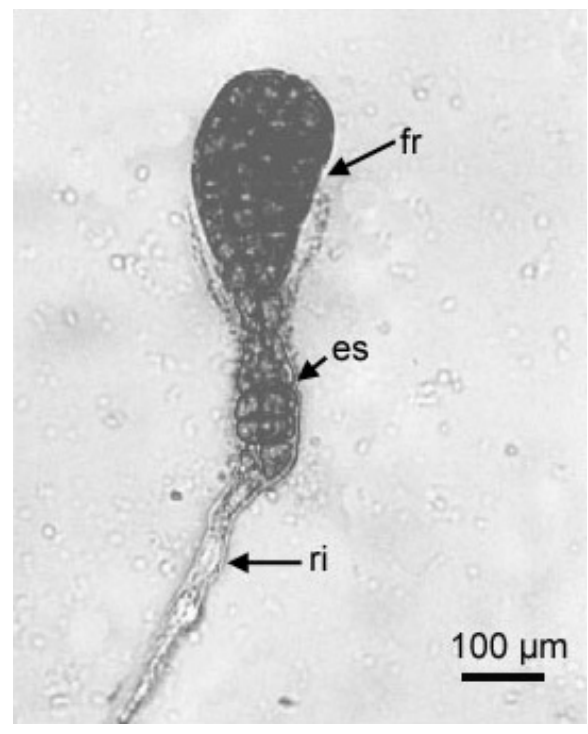

Figura 31

D. antarctica. Fronda juvenil multicelular de un mes, diferenciación de fronda (fr), estipe (es) y rizoide (ri). $200 \mathrm{x}$

D. antarctica. One-month old multicellular juvenile frond, showing differentiation of frond (fr), stipe (es) and rhizoid (ri). $200 \mathrm{x}$

también es conspicua en el polo apical de las plántulas, correspondiendo ésta a la pared celular vacía de la célula madre del cigoto, una vez desgarrada para dar paso al crecimiento de la célula del rizoide después de ocurrida la primera mitosis. Las plántulas así formadas, después de 4 semanas de incubación presentaron tres partes diferenciadas, fronda, estipe multicelular y 
rizoide (Fig. 31). Posteriormente aumentó el número de rizoides (Fig. 32); estos juveniles crecieron en el largo y ancho de su fronda multicelular y los rizoides se anastomosaron para conformar el disco basal multicelular que se evidenció después de 8 semanas en cultivo. Los embriones con el patrón de germinación con polaridad simétrica presentaron crecimiento y alargamiento, sin variación en su diámetro, polos redondeados, generalmente sin tabicaciones, distinguiéndose en los mas desarrollados una forma recta y una ligeramente curvada, todas abortivas (Figs. 33 y 34).

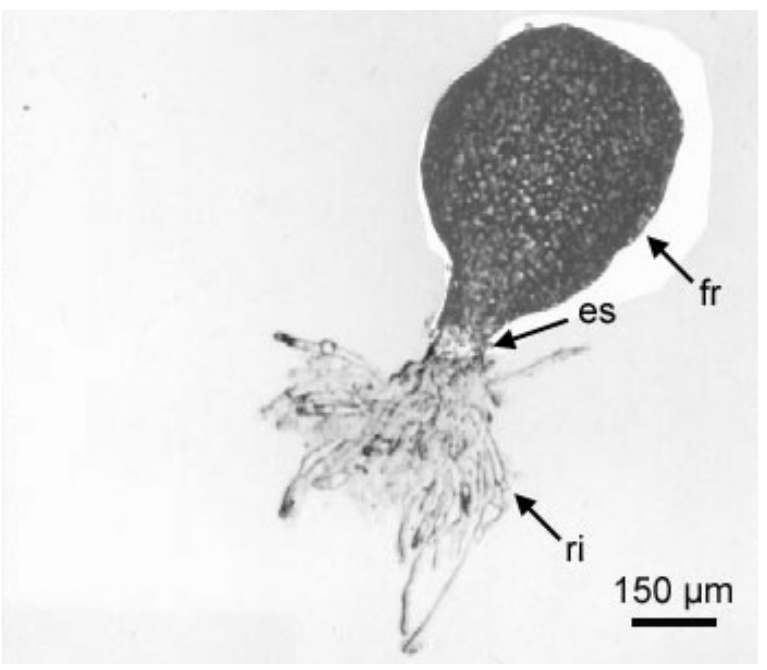

Figura 32

D. antarctica. Ejemplar juvenil de dos meses mostrando la fronda (fr), el estipe (es) y la proliferación de los rizoides (ri). $100 \mathrm{x}$

D. antarctica. Two-months old juvenile, showing frond (fr), stipe (es) and rhizoids proliferation (ri). x 100

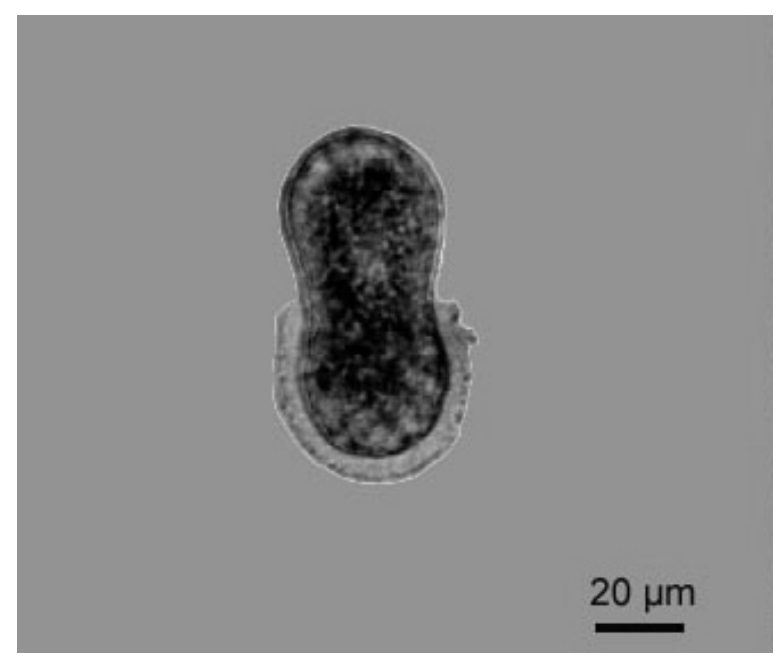

Figura 33

D. antarctica. Embrión anormal, primer estado. $400 \mathrm{x}$ D. antarctica. First stage of abnormal embryo. x 400

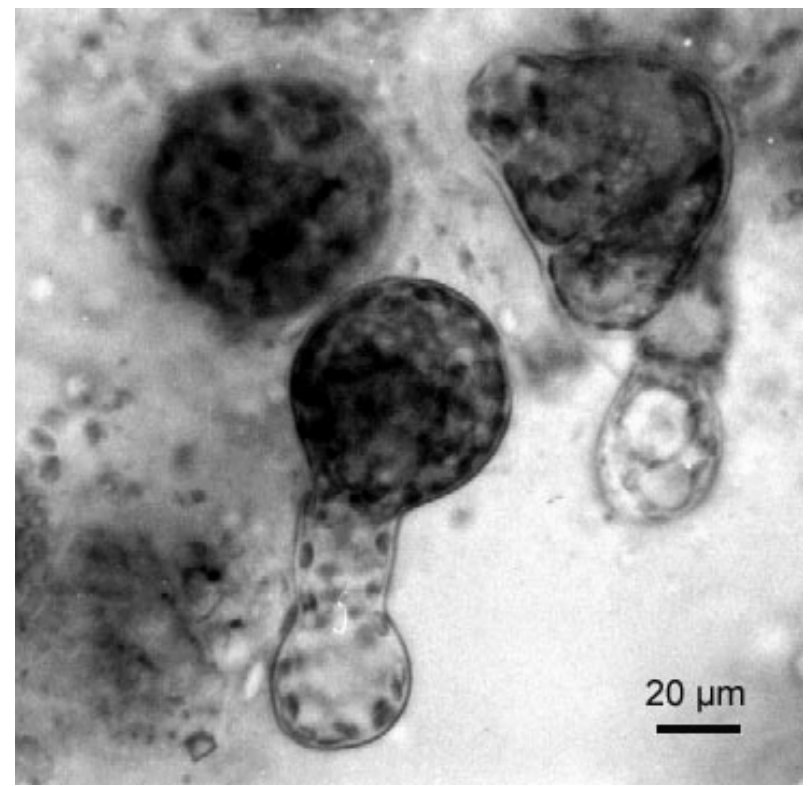

Figura 34

D. antarctica. Embrión anormal, estado final. $400 \mathrm{x}$

D. antarctica. Last stage of abnormal embryo. x 400

\section{Fertilización in vitro mediante cruzamiento de suspensiones de gametos, obtenidas desde trozos de frondas de ambos sexos incubadas separadamente}

Los resultados obtenidos en las pruebas de fertilidad realizadas con trozos provenientes de un total de 17 ejemplares intermareales de D. antarctica, en estados reproductivos maduros (3RM) (11 femeninas, 6 masculinas), recolectadas en los meses de mayo, junio y julio de 1999 y fertilizadas por mezcla de suspensiones de gametos obtenidas separadamente, presentaron oogonios tabicados con 4 oosferas y anteridios con 64 anterozoides respectivamente. Los gametos de ambos sexos se liberaron del endoquiton durante la incubación en agua de mar filtrada y estéril. Los anterozoides obtenidos se observaron inactivos libres o aglomerados en el bioensayo de mayo; no se logró liberación de éstos en junio y durante julio mostraron cierta actividad alrededor de las oosferas, sin lograr la fecundación. Los indicadores pre y post-fecundación en el mes de mayo fueron: oosferas libres sin membrana de fecundación (oo), un "ojo" (25\%); oosferas con membrana de fecundación (oomf), "dos ojos" (28\%); cigotos con polaridad (cp) (28\%); embriones con patrón simétrico de germinación (epsg) (18\%) y embriones con patrón asimétrico de germinación (epag) (1\%) (Tabla 2). 
Tabla 2

D. antarctica. Porcentajes de indicadores de fecundación después de mezclar gametos de ambos sexos obtenidos en suspensiones separadas después de $72 \mathrm{~h}$ de incubación

D. antarctica. Percentages of fertilization marks after mixing both sex gametes obtained separately after $72 \mathrm{~h}$ of incubation

\begin{tabular}{|c|c|c|c|c|c|c|}
\hline Meses & $\begin{array}{c}\mathrm{N}^{\mathrm{o}} \boldsymbol{\alpha} \mathrm{N}^{\mathrm{o}} \\
\text { Est. Reprod. }\end{array}$ & oo (\%) & oomf (\%) & cp (\%) & epsg (\%) & epag (\%) \\
\hline mayo/99 & $\begin{array}{c}4-1 \\
3 \mathrm{RM}\end{array}$ & 25 & 28 & 28 & 18 & 1 \\
\hline junio/99 & $3-2$ & 100 & 0 & 0 & 0 & 0 \\
\hline julio/99 & $\begin{array}{l}3 \mathrm{RM} \\
3 \mathrm{RM}\end{array}$ & 100 & 0 & 0 & 0 & 0 \\
\hline
\end{tabular}

oo = oosferas libres

oomf $=$ oosferas con membrana de fecundación

$\mathrm{cp}=$ cigoto con polaridad epsg = embrión con patrón simétrico de germinación epag $=$ embrión con patrón asimétrico de germinación

Table 3

D. antarctica. Cruzamiento de ejemplares y porcentajes de indicadores de fecundación obtenidos con gametos de ambos sexos obtenidos en la misma suspensión, después de 72 h de incubación

D. antarctica. Crossing fronds and percentages of fertilization marks from both sex gametes obtained in the same suspension,

\begin{tabular}{|c|c|c|c|c|c|c|c|c|}
\hline Meses & $\begin{array}{l}\mathrm{N}^{\circ} \alpha \mathrm{N}^{\mathrm{o}} \\
\text { Est. Reprod. }\end{array}$ & $\begin{array}{l}\mathrm{N}^{\circ} \text { cruza- } \\
\text { mientos }\end{array}$ & $\begin{array}{l}\mathrm{N}^{\circ} \text { cruza- } \\
\text { mientos }+\end{array}$ & oo (\%) & oomf $(\%)$ & $\operatorname{cp}(\%)$ & $\operatorname{epsg}(\%)$ & epag(\%) \\
\hline ago/99 & $\begin{array}{c}14-7 \\
3 \mathrm{RM}\end{array}$ & 7 & 5 & 70 & 0 & 21 & 1 & 8 \\
\hline sep/99 & $\begin{array}{c}12-8 \\
3 \mathrm{RM}\end{array}$ & 8 & 5 & 69 & 13 & 2 & 11 & 5 \\
\hline oct/99 & $\begin{array}{l}4-4 \\
4 \mathrm{RS} \\
\end{array}$ & 4 & 0 & 0 & 0 & 0 & 0 & 0 \\
\hline nov/99 & $\begin{array}{l}3-1 \\
4 \mathrm{RS}\end{array}$ & 1 & 0 & 0 & 0 & 0 & 0 & 0 \\
\hline dic/99 & $\begin{array}{l}2-1 \\
4 \mathrm{RS} \\
\end{array}$ & 1 & 0 & 0 & 0 & 0 & 0 & 0 \\
\hline ene $/ 00$ & $\begin{array}{l}2-1 \\
4 \mathrm{RS} \\
\end{array}$ & 1 & 0 & 0 & 0 & 0 & 0 & 0 \\
\hline $\mathrm{mar} / 00$ & $\begin{array}{l}1-4 \\
2 \mathrm{RI}\end{array}$ & 1 & 1 & 90 & 0 & 6 & 4 & 0 \\
\hline $\mathrm{abr} / 00$ & $\begin{array}{c}2-2 \\
\text { 2RI-3RM }\end{array}$ & 2 & 1 & 79 & 0 & 0 & 15 & 6 \\
\hline $\mathrm{may} / 00$ & $\begin{array}{l}2-2 \\
3 \mathrm{RM}\end{array}$ & 2 & 1 & 94 & 0 & 0 & 4 & 2 \\
\hline jun/00 & $\begin{array}{l}2-1 \\
3 \mathrm{RM} \\
\end{array}$ & 1 & 1 & 66 & 5 & 5 & 2 & 22 \\
\hline jul/00 & $\begin{array}{l}8-8 \\
3 \mathrm{RM} \\
\end{array}$ & 8 & 2 & 78 & 0 & 0 & 0 & 22 \\
\hline ago/00 & $\begin{array}{c}9-16 \\
\text { 3RM-4RS }\end{array}$ & 9 & 3 & 87 & 0 & 0 & 0 & 13 \\
\hline $\mathrm{sep} / 00$ & $\begin{array}{c}11-8 \\
\text { 3RM-4RS } \\
\end{array}$ & 8 & 1 & 100 & 0 & 0 & 0 & 0 \\
\hline
\end{tabular}




\section{Fertilización in vitro mediante gametos obtenidos del cruzamiento de trozos de fronda de ambos sexos}

Los resultados obtenidos con trozos provenientes de un total de 135 ejemplares intermareales de $D$. antarctica, en diferentes estados reproductivos (72 femeninas, 63 masculinas), recolectadas en el intermareal en los meses de agosto/99 a septiembre/00 y fecundadas in vitro, indican que el número de cruzamientos positivos siempre es menor o raramente igual al número de intentos por mes realizados (Tabla 3). Todos los indicadores pre y post-fecundación se detectaron en septiembre/99 y en junio/00 cuando se trabajó con estados reproductivos maduros (3RM) siendo menores los porcentajes de los embriones con patrón asimétrico de germinación (epag 5\%) que los embriones con patrón simétrico de germinación (epsg 11\%) en septiembre /99, a diferencia de junio/00 en que predominaron los embriones con patrón asimétrico de germinación (epag $22 \%$ ). Desde octubre/99 a enero/00 la disponibilidad de ejemplares reproductivos accesibles cada mes simultáneamente fue muy baja. Se intentó la fertilización con estados reproductivos senescentes (4RS) y los cruzamientos resultaron negativos en la detección de todos los indicadores pre y post fecundación. El indicador pre fecundación, oosfera (oo) se presentó en los meses de invierno agosto/99 a septiembre/99 y en otoño e invierno, marzo/00 a septiembre/00, excepto en primavera y verano, octubre/99 a enero/00. En marzo/00 y abril/00 se logró recolectar estados reproductivos inmaduros (2RI) y (2RI-3RM); se obtuvieron embriones con polaridad simétrica (epsg 4\%) en el primero y de ambos tipos en el segundo (epsg 15\% y epag 6\%) respectivamente. En mayo/00, con ejemplares en estado reproductivo maduro (3RM), se obtuvieron embriones de ambos tipos (epsg 4\%) y (epag 2\%). En julio/00 y agosto/00 con cruzamiento de ejemplares maduros en el primero (3RM) y maduros y senescentes en el segundo (3RM-4RS), se obtuvieron embriones con patrón asimétrico de germinación (epag 22\% y $13 \%$ ) respectivamente. Los indicadores post fecundación volvieron a ser negativos en septiembre/00, aunque el porcentaje de oosferas libres (oo) fue alto $(100 \%)$ y los ejemplares estaban aún en estados reproductivo maduro (3RM) y reproductivo senescente (4RS).

Los resultados obtenidos con material recolectado a partir de 55 ejemplares varados en junio 2000, en estado de madurez (3RM) y (4RS), indican la liberación de gametos femeninos aunque no siempre acompañados de gametos masculinos. Los indicadores de fecundación señalan oosferas libres (oo), (73\%) y embriones con el patrón de polaridad asimétrica (epag) (27\%) (Tabla 4).

Los resultados indican la existencia de períodos marcados, infértil coincidiendo con fines de primavera y verano, caracterizado por la no producción de gametos y por la coincidencia con el período de término de maduración de los especímenes y el período de reposo reproductivo (Figs. 18 y 19, Tablas 1 y 5) y fértil, caracterizado por la producción de gametos (oo) y embriones con polaridad asimétrica (epag) considerados normales, en todos los meses excepto marzo/00.

\section{Censo de ejemplares $(>50 \mathrm{~cm})$}

El área intermareal rocosa de la localidad de Montemar fue calculada en $2725 \mathrm{~m}^{2}$, en los cuales se estimó la presencia de aproximadamente 300 ejemplares, en diciembre 2000. A diferencia de estos resultados, la estimación para los años 1993/94, para la misma área correspondió aproximadamente a 500 ejemplares.

\section{Tabla 4}

D. antarctica. Cruzamiento de ejemplares varados y porcentajes de indicadores de fecundación con gametos de ambos sexos obtenidos en la misma suspensión, después de $\mathbf{7 2}$ h de incubación

D. antarctica. Crossing of drift fronds and percentages of fertilization marks from both sex gametes obtained in the same suspension, after $72 \mathrm{~h}$ of incubation

\begin{tabular}{|c|c|c|c|c|c|c|c|c|}
\hline Mes & $\begin{array}{l}\mathrm{N}^{\circ} \propto \mathrm{N}^{\mathrm{o}} \\
\text { Est. Reprod. }\end{array}$ & $\begin{array}{l}\mathrm{N}^{\circ} \text { cruza- } \\
\text { mientos }\end{array}$ & $\begin{array}{l}\mathrm{N}^{\circ} \text { cruza- } \\
\text { mientos }+\end{array}$ & oo (\%) & $\operatorname{oomf}(\%)$ & $\mathrm{cp}(\%)$ & epag(\%) & $\operatorname{epsg}(\%)$ \\
\hline jun/00 & $\begin{array}{c}29-26 \\
3 R M-4 S\end{array}$ & 26 & 8 & 73 & 0 & 0 & 0 & 27 \\
\hline $\begin{array}{l}\text { oo } \\
\text { oomf } \\
\text { cp }\end{array}$ & $\begin{array}{l}\text { as libres } \\
\text { as con men } \\
\text { con polari }\end{array}$ & de fe & ación & $\begin{array}{l}\text { epsg } \\
\text { epag }\end{array}$ & $\begin{array}{l}\text { mbrión } \\
\text { mbrión }\end{array}$ & $\begin{array}{l}\text { atrón } \\
\text { atrón }\end{array}$ & $\begin{array}{l}\text { étrico de } \\
\text { nétrico de }\end{array}$ & $\begin{array}{l}\text { minación } \\
\text { rminación }\end{array}$ \\
\hline
\end{tabular}


Tabla 5

D. antarctica. Períodos fértiles e infértiles. Flujo de desarrollo desde oosferas hasta embriones

D. antarctica. Fertile and infertile periods. Flux of development from oosphere to embryo stage

\begin{tabular}{|c|c|c|}
\hline $\begin{array}{c}\text { oo } \rightarrow \rightarrow \rightarrow \rightarrow \text { cp } \rightarrow \text { epag* } \rightarrow \\
y \text { epsg }\end{array}$ & agosto/99 & $\begin{array}{l}\text { Período } \\
\text { fértil }\end{array}$ \\
\hline \multirow[t]{6}{*}{$\begin{aligned} \text { oo } \rightarrow \text { oomf } \rightarrow \text { cp } & \rightarrow \text { epag* } \\
& \rightarrow \text { epsg }\end{aligned}$} & septiembre/99 & \\
\hline & octubre/99 & \begin{tabular}{|l|} 
Período \\
infértil
\end{tabular} \\
\hline & noviembre/99 & \\
\hline & diciembre/99 & \\
\hline & enero/00 & \\
\hline & febrero/00 & \\
\hline oo $\rightarrow \rightarrow \rightarrow \rightarrow \mathrm{cp} \rightarrow$ epsg & marzo/00 & $\begin{array}{l}\text { Período } \\
\text { fértil }\end{array}$ \\
\hline $\begin{aligned} \text { oo } \rightarrow \rightarrow \rightarrow \rightarrow \rightarrow & \rightarrow \text { epag* } \rightarrow \\
& y \text { epsg }\end{aligned}$ & abril/00 & \\
\hline $\begin{aligned} \text { oo } \rightarrow \rightarrow \rightarrow \rightarrow \rightarrow & \rightarrow \text { epag* } \rightarrow \\
& \text { ע epsg }\end{aligned}$ & mayo/00 & \\
\hline $\begin{aligned} \text { oo } \rightarrow \text { oomf } \rightarrow \text { cp } & \rightarrow \text { epag* } \rightarrow \\
& \searrow \text { epsg }\end{aligned}$ & junio/00 & \\
\hline oo $\rightarrow \rightarrow \rightarrow \rightarrow \rightarrow \rightarrow$ epag* $\rightarrow$ & julio/00 & \\
\hline oo $\rightarrow \rightarrow \rightarrow \rightarrow \rightarrow \rightarrow$ epag* $\rightarrow$ & agosto/00 & \\
\hline $\mathrm{OO} \rightarrow \rightarrow \rightarrow \rightarrow \rightarrow \rightarrow$ & septiembre/00 & \\
\hline \multicolumn{3}{|c|}{$\begin{array}{ll}\text { oo } & =\text { oosferas libres } \\
\text { oomf } & =\text { oosferas con membrana de fecundación } \\
\mathrm{cp} & =\text { cigoto con polaridad } \\
\text { epsg } & =\text { embrión con patrón simétrico de germinación }=\text { embrión anormal } \\
\text { epag* } & =\text { embrión con patrón asimétrico de germinación }=\text { embrión normal } \\
\rightarrow \quad & =\text { dirección desarrollo normal, } \boldsymbol{\Downarrow}=\text { dirección de desarrollo anormal }\end{array}$} \\
\hline
\end{tabular}

\section{Discusión y Conclusiones}

\section{Historia de vida de $D$. antarctica}

De acuerdo a los resultados obtenidos en este estudio, la historia de vida de $D$. antarctica (Fig. 35), básicamente es la misma que caracteriza al Orden Fucales, al cual inicialmente estuvo adscrita. Los ejemplares generalmente son dioicos, con reproducción oógama; sin embargo, la génesis del conceptáculo reproductivo es marcadamente diferente. En Fucales, su desarrollo se inicia por una célula apical situada en el fondo de una pequeña depresión o cripta, generalmente ubicada en los extremos superiores de las ramificaciones del talo; esta célula porta un pseudo pelo hialino, mitosis sucesivas con tabicaciones longitudinales la replican así como también al pseudo pelo hasta conformar la cripta pilífera propiamente tal. En cambio, en $D$. antarctica, de acuerdo a lo observado en este trabajo, el desarrollo de los conceptáculos es endógeno y se puede presentar sobre ambas caras de las frondas y látigos. Este origen y desarrollo del conceptáculo de $D$. antarctica de la costa central de Chile, coincide con lo expresado por Petrov
(1967) y Nizamuddin (1968) quienes para la misma especie, indican que la célula inicial se encuentra ubicada bajo varias capas de células bajo la superficie del talo y los conceptáculos generalmente dioicos están repartidos en todas las láminas. En este estudio, el seguimiento de conceptáculos en diferentes etapas de desarrollo demostró que la diferenciación del conceptáculo comienza en estratos de células ubicados en la corteza interna (Fig. 3); allí, por divisiones sucesivas de las filas de células, se diferencia un conglomerado celular. El mayor crecimiento por las ramificaciones hace que las filas de células se arqueen y perfilen en su porción central un eje imaginario, un lumen inicialmente longitudinal, cuyo crecimiento en diámetro avanza hasta tomar una forma ovoide de fondo cóncavo o plano; al mismo tiempo, el cuello del lumen se abre paso entre las células de la corteza, desembocando en un poro de salida u ostíolo a nivel del meristoderma. Naylor (1953) y Clayton et al. (1987) describen para D. antarctica y D. willana de Nueva Zelanda y $D$. potatorum, una iniciación de los primeros estados del conceptáculo debido a la ocurrencia de ramificaciones continuas en células meristodérmicas y su ontogenia de desarrollo es descrita por Clayton et al. (1987), de manera que las ramas más viejas quedan incorporadas en la corteza y en su enfrentamiento con el centro del futuro conceptáculo se arquean hacia adentro producto de su alta tasa de crecimiento en comparación con la de los filamentos de células vegetativas.

La diferenciación de las estructuras reproductivas es también muy similar en Fucales y Durvillaeales. En este trabajo se describe por primera vez en $D$. antarctica la diferenciación de los anteridios y oogonios. Los anteridios se inician con una meiosis seguida de cuatro mitosis sucesivas, lo que da como resultado la formación de 64 anterozoides biflagelados, ubicados en un compartimento conformado por endoquiton al interior y exoquiton al exterior (Figs. 5, 6, 7 y 35). Los oogonios se inician con una meiosis seguida de una mitosis sin citodiéresis, lo que da como resultado la formación de cuatro oosferas binucledas (Figs. 9, $10 \mathrm{y}$ 35 ), ubicadas respectivamente en cuatro compartimentos conformados por endoquiton al interior y exoquiton al exterior. Los oogonios en vista frontal presentan cuatro oosferas distribuídas de una manera particular, dos en el centro y una en cada extremo, de manera que en vista lateral sólo se observa una fila con tres de ellas. Este resultado de acuerdo con los patrones de alternativas de producción de oosferas de Fucales, nos permite ubicar a D. antarctica junto con Xiphophora, Hormosira, Bifurcariopsis y Ascophyllum de las Fucales (Cheshire \& Conran. 1995), todos con oogonios con cuatro oosferas y cuatro núcleos reduccionales. Estos últimos extruídos como super numerarios a la periferia de ellas en Ascophylum (Smith 1955), y observados en este estudio en el citoplasma de las oosferas en $D$. 
antarctica; siendo también diferente la ubicación de las oosferas, tetraédricas en Ascophyllum (Smith 1955), una en cada extremo y dos en el centro, en $D$. antarctica. La reducción del número de huevos fue considerada una característica evolucionada en Fucales, siendo Fucus el tipo ancestral, con ocho oosferas uninucleadas; sin embargo, de acuerdo a características ultraestructurales del flagelo del espermio, Manton (1964) sugiere que en Fucales, Fucus es un tipo derivado y Cystoseira es el género más primitivo. Un análisis cladístico de la evolución y biogeografía de Durvillaea en el cual se usaron 29 caracteres morfológicos, reproductivos, anatómicos y habitat de Durvillaeales y las Fucales, Fucus, Xiphophora y Bifurcariopsis, como grupo externo, sugiere que Durvillaea evolucionó en el hemisferio Sur estando bien establecido antes de la disociación de Nueva Zelanda de Gondwana (Cheshire \& Conran 1995).

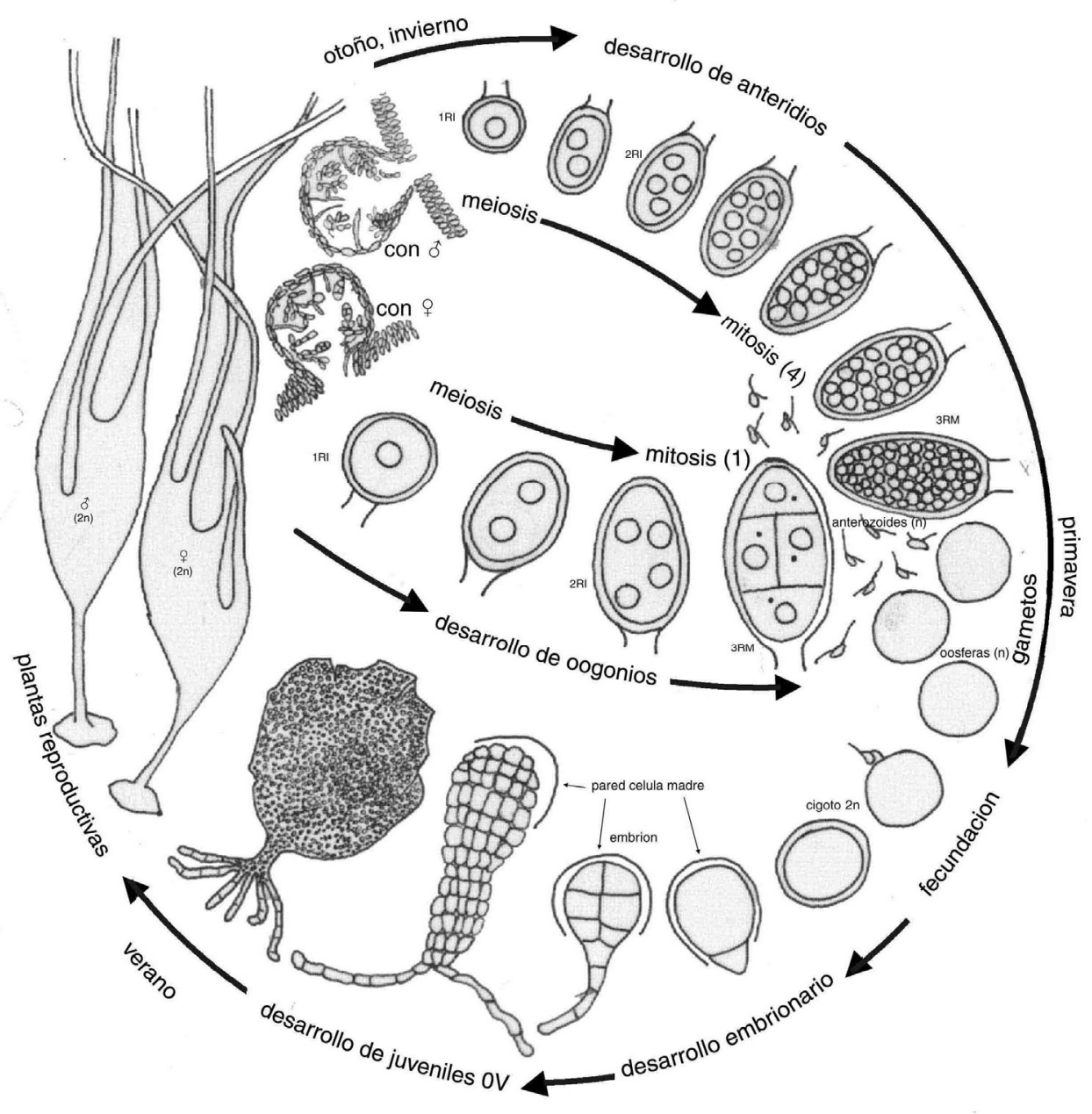

Figura 35

D. antarctica. Historia de vida. Ejemplar masculino ( ) $)$, ejemplar femenino $(\alpha)$, conceptáculo masculino (con), conceptáculo femenino (con), fenología de la secuencia de desarrollo de células germinativas de anteridios y oogonios en estado reproductivo inmaduro (1RI), estado reproductivo inmaduro (2RI), estado reproductivo maduro (3RM); producción de anterozoides y oosferas; fecundación, cigoto, desarrollo de embriones, ejemplares juveniles $(0 \mathrm{~V})$ y reproductivos. (n)= haploide, $(2 n)=$ diploide

D. antarctica. Life History. Male frond ( ), female frond $(\alpha)$, male conceptacle (con), female conceptacle (con), phenology of development of germinative cells of antheridia and oogonia from inmature stage (1RI), inmature stage (2RI), mature stage (3RI); production of antherozoids and oospheres; fertilization, zygote, development of embryo, juveniles $(0 \mathrm{~V})$ and reproductive specimens.

$$
(\mathbf{n})=\text { haploid, }(\mathbf{2 n})=\text { diploid }
$$


De acuerdo a los resultados obtenidos en este trabajo, en la historia de vida de $D$. antarctica, las etapas de la gametogénesis y consecuentemente la presencia y el estado de desarrollo de los conceptáculos son buenos indicadores de la madurez de los ejemplares, distinguiéndose estados vegetativos $(0 \mathrm{~V})$, reproductivos inmaduros (1RI, 2RI), maduros (3RM) y senescentes (4RS) (Fig. 35). Estos criterios propios de la ontogenia reproductiva de organismos animales se aplican por primera vez en algas. En $D$. antarctica el término estado reproductivo ha sido referido a ejemplares con conceptáculos sin efectuar un estudio detallado del estado de madurez de los mismos (Bushmann 1982, Santelices et al. 1980, Alveal et al. 1990a, Westermeier et al. 1994, Collantes et al. 1997). En este trabajo la escala de madurez indica que los ejemplares en estados (1RI), (2RI) y (4RS) presentan conceptáculos pero éstos se encuentran inmaduros y senescentes respectivamente, por tanto su presencia no es un buen indicador de la fertilidad de los especímenes, aunque pueden considerarse como indicadores de potencial reproductivo.

Las observaciones realizadas en este trabajo, muestran que los gametos de $D$. antarctica al momento de la maduración, en las condiciones de laboratorio usadas, son expulsados desde los conceptáculos como anterozoides libres o contenidos en el interior de los anteridios y como oosferas libres o empaquetadas en los oogonios. Los gametos al interior de anteridios y oogonios quedan libres después de $30-60$ s en contacto con el agua, saliendo los anterozoides pausadamente por el único poro de salida del endoquiton y las oosferas extruyendo lenta o abruptamente cada una desde su propio compartimento del endoquiton. Sólo en el caso de las oosferas, Naylor (1953) hace para ellas una detallada descripción de su liberación, la cual es coincidente con lo observado en este trabajo. En el caso de los oogonios también se confirma la descripción de oosferas angulares mientras se encuentran en el interior de los conceptáculos, protegidas por el exoquiton y oosferas esféricas en los oogonios libres, en contacto con el agua cubierto sólo por el endoquiton (Naylor 1953); esta característica es propia de células en proceso de hidratación lo cual, en este caso, induce por aumento de volumen el rompimiento del endoquiton y la liberación de un protoplasto, la oosfera cubierta sólo por un delgado periplasto (Fig. 26). Esto concuerda con lo descrito por Clayton \& Ashburner (1994) para huevos de $D$. potatorum que presentan una membrana delgada visible al microscopio óptico.

En este estudio en $D$. antarctica, los gametos masculinos libres se presentaron activos e inactivos. Los primeros se acercaron y fecundaron a las oosferas, los otros se mantuvieron aglomerados e inmóviles. Esta observación confirma que la presencia de conceptáculos en las frondas no siempre es indicativa de madurez, aunque los gametos provengan de estados reproductivos maduros (3RM). Este fenómeno podría explicarse por inmadurez de los gametos, es decir, no se encuentran viables $\mathrm{o}$ en estado óptimo de capacitación para fecundar a las oosferas o provienen de un estado reproductivo inmaduro (2RM), de los cuales fue posible observar anteridios de menos de 32 células liberando sus anterozoides. La inactivación de los gametos masculinos, durante el proceso de liberación de éstos pudo deberse a la existencia de una comunicación deficiente entre gametos masculinos y femeninos, es decir, los sistemas de comunicación hormonales y/o de receptores bioquímicos no han sido activados. La presencia de feromonas, fucoserrateno y la interacción entre proteínas derivadas del anterozoide que reconocen glicoconjugados sulfatados en la membrana de los huevos ha sido descrita para Fucus (Müller \& Luthe 1981, Wright et al. 1995 a y b). Se han descrito también hormonas sexuales del tipo hormosireno para el género Durvillaea, responsable de la descarga y posterior atracción de los gametos masculinos hacia los huevos (Müller \& Luthe 1981, Müller et al. 1985).

En el proceso post-fecundación observado en este trabajo, D. antarctica se caracteriza por la inmediata secreción de un halo mucilaginoso alrededor del cigoto formado; Clayton \& Ashburner (1994) indican que en $D$. potatorum se trata de la secreción masiva de compuestos fenólicos. El fenómeno de exocitosis masiva de vesículas periféricas fenólicas, después de la fertilización se piensa es comparable con la descarga de vesículas corticales en huevos de erizos de mar. Este proceso tendría relación con la formación de membrana vitelina, que impide la poliespermia (Schuel 1978, Longo et al. 1986).

Después de ocurrida la fecundación en $D$. antarctica el halo de fertilización es evidente y apreciable, desde el preciso instante en que la oosfera es pinchada por el flagelo corto del anterozoide (Fig. 27). La membrana de fecundación es en $D$. antarctica uno de los indicadores post-fecundación positivo, visible bajo microscopía óptica, determinante de la condición de cigoto (Tablas 2, 3 y 4), aunque no se descarta que efectos mecánicos de manipulación puedan provocar también el fenómeno.

En este estudio se describen para $D$. antarctica tamaños variables de oosferas, pequeñas $(16 \mu \mathrm{m})$ medianas $(25 \mu \mathrm{m})$ y grandes $(36 \mu \mathrm{m})$. Este hecho ha sido antes mencionado para Fucus, en el cual el diámetro de ellas determinan diferentes patrones de germinación. Es así como las más pequeñas desarrollan divisiones celulares de fronda antes de la diferenciación del rizoide, en cambio las más grandes desarrollan fronda y rizoide simultáneamente, finalmente presentando ambas 
patrones de germinación normales (López-Rodas \& Costas 1995, Graham \& Wilcox 2000). Al igual que en Fucus, en D. antarctica es posible que los distintos tamaños de oosferas generen patrones de germinación diferentes, hecho, en este estudio, no comprobado.

En D. antarctica inicialmente después de la fecundación (24 h) los cigotos se mantuvieron esféricos sin signos de polarización, equivalente a lo descrito para Fucus en que durante esta etapa del desarrollo normal los cigotos jóvenes no muestran asimetría o polaridad detectable (Costas et al. 1994). Esta aseveración indica que en el período inicial de germinación, la polaridad no es en Durvillaea un buen indicador de la fecundación lograda como lo expresara Naylor (1953) y Nakasawa (1962) para huevos de Durvillaea y Sargassum respectivamente, concluyéndose que la polaridad es un indicador post fecundación positivo sólo después de 24 a $48 \mathrm{~h}$ de desarrollo (Tablas 2, 3 y 4).

En $D$. antarctica, a las $2 \mathrm{~h}$ de fecundación el halo se hizo más denso y la membrana de fecundación originó una pared celular (Fig. 27), sus componentes podrían ser equivalentes a los contenidos en dos tipos de vesículas relacionadas con la formación de pared en Fucus, unas conteniendo fucoidanos y las otras ácido algínico y probablemente polifenoles (taninas), las cuales descargan sus contenidos en la pared celular en formación (Quatrano \& Stevens 1976). En los embriones observados de $D$. antarctica, el polo que diferenció el rizoide presentó una pared más gruesa y una capa amplia de mucílago disperso (Fig. 29), presumiblemente para la adhesión al sustrato, similar al fenómeno descrito para Halidrys siliquosa, en que la rápida producción de mucílago adhesivo mantiene anclados los cigotos al sustrato, previniendo que sean arrastrados por las olas o se hundan en el mar (Hardy \& Moss 1978). También en algas pardas se ha postulado que los cuerpos fenólicos pueden establecer interacciones con el alginato colaborando en el establecimiento de la pared y su consistencia e interviniendo en la adhesión al sustrato (Vreeland et al. 1998). La formación de pared celular es un fenómeno ligado a la formación y fijación de la polaridad; este hecho ha sido ampliamente estudiado para Fucus, donde se ha establecido que la formación de pared celular es indispensable para la formación del rizoide, determinación de polaridad celular y establecimiento del primer plano de división celular (Quatrano 1972, Kropf et al. 1988, Quatrano \& Shaw 1997). Así también, los resultados obtenidos en este estudio establecen que la formación de pared es un evento crítico para el desarrollo de embriones normales de $D$. antarctica, los cuales deben desarrollar polaridad asimétrica. Los embriones normales (epag) de D. antarctica luego de tres semanas de cultivo mediante mitosis con tabicaciones transversales y longitudinales, se diferencian en tres partes, las células superiores en fronda, las células medias en estipe y las células basales incoloras en rizoide ( Fig. 31).

\section{Fenología de la maduración de conceptáculos}

De acuerdo a estos resultados, los caracteres morfológicos macroscópicos, utilizados en terreno para seleccionar ejemplares juveniles $(<50 \mathrm{~cm}$, textura lisa sin conceptáculos) y adultos $(>50 \mathrm{~cm}$, textura punteada y/o porosa con conceptáculos) fueron válidos sólo para el caso de los juveniles, siendo necesario en el caso de los adultos el análisis histológico. Estos últimos pueden corresponder indistintamente a ejemplares reproductivos inmaduros (1RI), en desarrollo (2RI), reproductivos maduros (3RM) y reproductivos senescentes (4RS). En consecuencia el término estado reproductivo no es sinónimo de madurez en $D$. antarctica, ajustándose estrictamente a este sólo los ejemplares reproductivos maduros (3RM). El envejecimiento del conceptáculo se caracteriza por un aumento de hifas y de sustancias fenólicas en tejidos a nivel de la corteza, cuyo propósito es el de ocluir la entrada, hecho descrito para el género Durvillaea por Naylor (1953), Hay (1979) y Clayton et al. (1987). Otras señales indicadoras del estado de senescencia constatadas en este trabajo son la carencia de anteridios $u$ oogonios, abundantes restos de exoquiton adheridos a los ramilletes de hifas en el interior de los conceptáculos y una disminución secuencial del diámetro del lumen. Estas características constituyen signos inequívocos del final del período fértil de D. antarctica en Chile central. El período de senescencia de los conceptáculos descrito en este estudio, durante fines de primavera y verano, concuerda con lo señalado por Collantes et al. (1997) para la misma localidad.

Al contrastar el análisis de estados vegetativos y reproductivos de 101 ejemplares varados en el mes de julio 2001 (Fig. 20), con los datos del mismo mes en 1997 efectuado con ejemplares intermareales (Fig. 19), encontramos en los varados la gama completa de estados vegetativo y reproductivos (0V, 1RI, 2RI, 3RM y 4RS) y en los intermareales sólo estados reproductivos (1RI, 2RI, 3RM) no detectándose estados vegetativos ni senescentes $(0 \mathrm{~V}, 4 \mathrm{RS})$. Es interesante en los ejemplares varados, el mayor número de estratos con conceptáculos que indicarían que la mayoría de estos no corresponden a la población intermareal de caleta Montemar generalmente con un estrato de conceptáculos (Figs. 8, 11 y 36) sino probablemente a especímenes del submareal de esta localidad o aledañas (Figs. 20, $37 \mathrm{y}$ 38). 


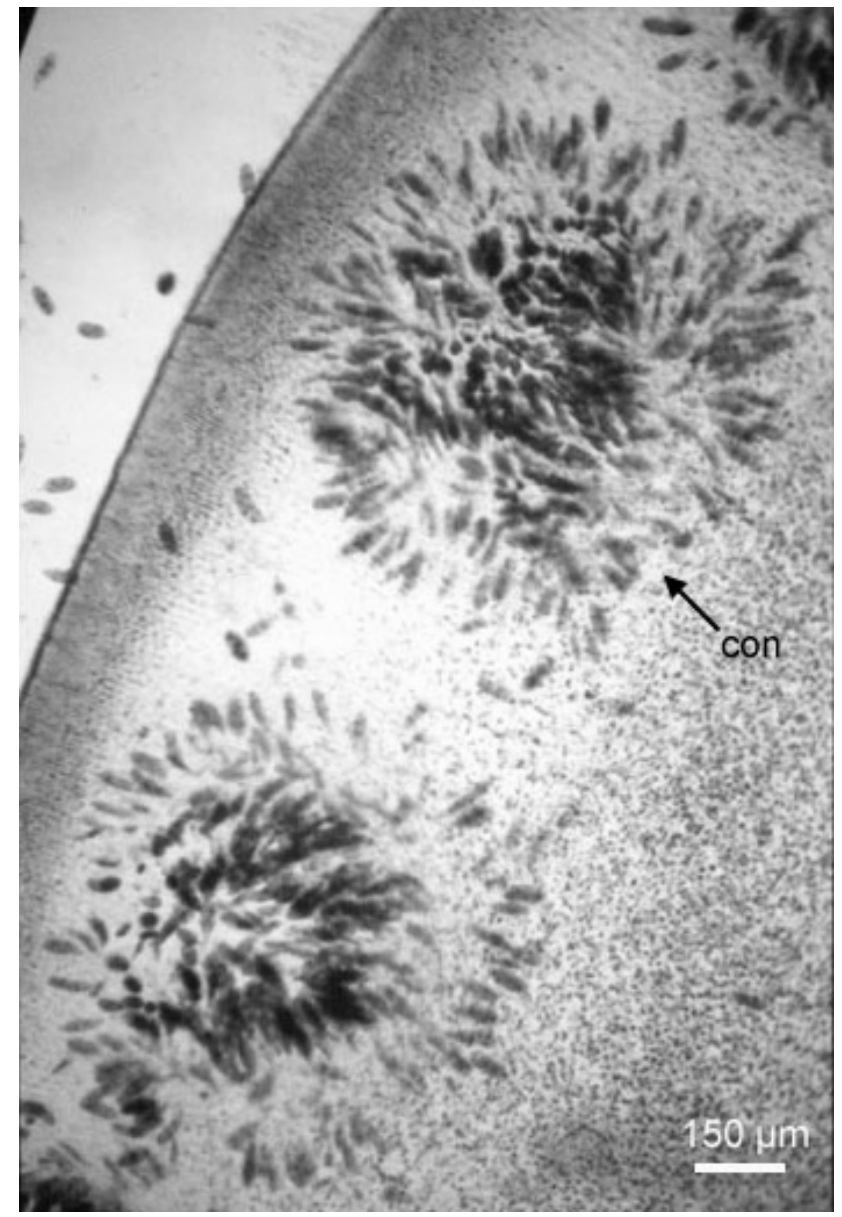

Figura 36

D. antarctica. Corte transversal de una fronda reproductiva con un estrato de conceptáculos (con) indicando un período reproductivo. $40 \mathrm{x}$

D. antarctica. Transversal section of reproductive frond with one layer of conceptacles (con) showing one reproductive period. $\mathrm{x} 40$

Datos de fenología reproductiva de $D$. antarctica en la playa El Encanto, vecina a caleta Montemar, en julio del año 1997, indican la presencia en el intermareal de una población con estados reproductivos $(0 \mathrm{~V}, 1 \mathrm{RI}, 2 \mathrm{RI}$, 3RM) (Merino 2000) y datos no publicados de los autores de este estudio señalan un estrato de conceptáculos, lo que en parte también confirmarían que especímenes del intermareal de esta localidad no fueron los principales constituyentes de la varazón de $D$. antarctica estudiada.

Naylor (1953) señala que es posible determinar el número de períodos fértiles en la historia de vida de $D$. antarctica y D. willana, pues al ocluirse el conceptáculo senescente, éste queda sepultado entre la corteza y la médula, conformándose estratos de conceptáculos inactivos que indicarían la edad de los ejemplares. Los conceptáculos observados por Collantes et al. (1997) y

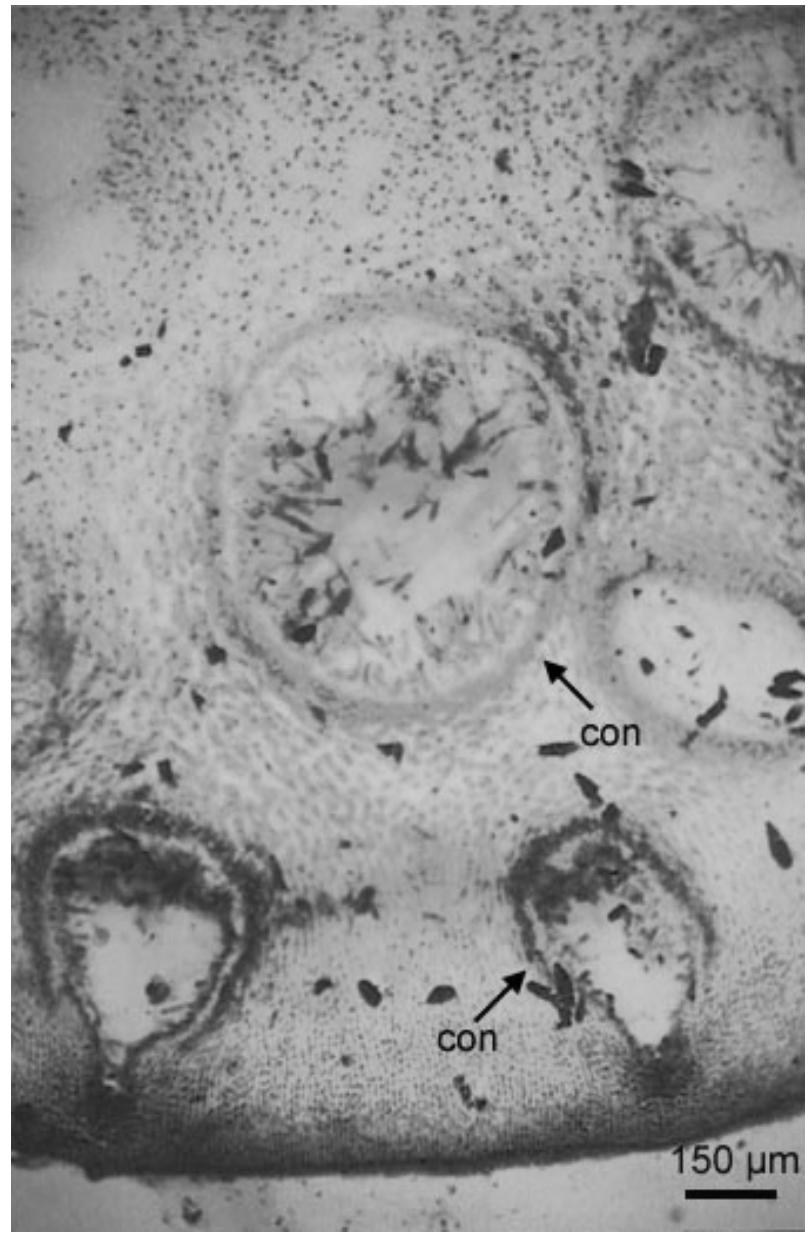

Figura 37

D. antarctica. Corte transversal de una fronda reproductiva con dos estratos de conceptáculos (con), indicando dos períodos reproductivos. $40 \mathrm{x}$

D. antarctica. Transversal section of reproductive frond with two layers of conceptacles (con) showing two reproductive periods. $\mathrm{x} 40$

en este estudio, para los ejemplares intermareales de la localidad de Montemar, generalmente presentaron un sólo estrato de conceptáculos; sin embargo, también se observaron algunos ejemplares $(2 \%)$, en los cuales se apreciaron claramente dos estratos, el inferior ocluído y senescente, el superior maduro o en proceso de maduración. Esto indicaría para estos ejemplares con dos estratos de conceptáculos, una edad aproximada de dos años corroborada por los datos de fenología reproductiva de este trabajo que indican la existencia en el área intermareal de caleta Montemar, de una población de $D$. antarctica anual o bianualmente renovada. En el primer caso, constituida por ejemplares vegetativos $(0 \mathrm{~V})$ en proceso de crecimiento que pueden llegar en un tiempo no menor a 8 meses, dependiendo de la fecha de su reclutamiento, a ser estados reproductivos maduros (Tabla 1). Estos continuan 
avanzando en el período reproductivo con una secuencia inicial creciente de estados vegetativos $(0 \mathrm{~V})$ y reproductivos en las que es posible encontrar estados inmaduros y en maduración (1RI, 2RI, 3RM) desde marzo/97 y/o abril/97 hasta julio/97; seguido de un período en que los ejemplares vegetativos $(0 \mathrm{~V})$ detienen su flujo de maduración (inicio del cese de maduración), hecho que se constata por la ausencia de ejemplares (1RI) y presencia de ejemplares (2RI y 3RM) en agosto/97 y septiembre/97, seguido finalmente del término del período reproductivo de maduración con estados maduros y senescentes (3RM y 4RS) en el mes de octubre/97 (término de la maduración). En el segundo caso, constituidas por parte de los ejemplares vegetativos $(0 \mathrm{~V})$ en proceso de crecimiento que no alcanzan a completar la maduración de sus conceptáculos por ser reclutas tardíos. Las frondas vegetativas $(0 \mathrm{~V})$ que al mes de julio/97 no siguen el flujo de maduración respectivo y continuan vegetativas, son los reclutas rezagados que entrarán con edad aproximada de 8 meses al período reproductivo del año siguiente, entonces preparadas para su maduración y que explicarían la rápida secuencia de ejemplares en todos los estados de maduración (1RI, 2RI, 3RM) durante los meses marzo/97 y/o abril/97 a julio/97.

En el flujo de estados vegetativos y reproductivos intermareales desde marzo/97 a marzo/98, llama la atención las diferencias en la distribución de los estados reproductivos en estos meses, lo que indicaría para este último, un retraso en la entrada en maduración de los ejemplares intermareales, por estar presentes estados senescentes (4RS) y vegetativos (0V) y faltar estados reproductivos de maduración (Fig. 19). Los resultados de marzo/97 con estados vegetativos $(0 \mathrm{~V})$ y reproductivos (1RI, 2RI, 3RM) indicarían que la madurez se desencadena y desarrolla con rapidez, probablemente en períodos cortos de días al término del verano e inicio del otoño, y las diferencias en velocidad de maduración entre estados se deberían a diferencias en edades en meses de los especímenes vegetativos $(0 \mathrm{~V})$ según el reclutamiento del año anterior y que no alcanzaron a entrar en maduración, o por la presencia de ejemplares 4RS que entran en el año segundo de su flujo de maduración. El seguimiento de 6 sobrevientes de 20 reclutas de tamaños de $10 \mathrm{~cm}$ de la población intermareal de caleta Montemar desde octubre de 1997, indicó que los especímenes alcanzaron estados reproductivos 1RI y 2RI en marzo y abril del año siguiente. La anualidad o bianualidad de la población intermareal de $D$. antarctica se explicaría por la frecuente remoción de especímenes intermareales por efecto de la dinámica de oleaje e interacciones bióticas de depredación humana (aunque se trate de un área protegida), herbívoría y competencia con L. nigrescens. Por otra parte los resultados obtenidos del análisis histológico de la varazón de ejemplares de la población submareal de $D$. antarctica, presentó uno, dos y tres estratos reproductivos que indicarían de acuerdo a lo expresado por Naylor (1953), edades de uno, dos y tres años respectivamente (Figs. $20,36,37$ y 38$)$.

La diferencia en rangos de edades entre la población intermareal y las frondas varadas presumiblemente con un componente submareal demostraría para estas últimas, un hábitat con condiciones bióticas y abióticas más estables que en el intermareal, permitiendo a esta población alcanzar edades superiores, lo cual amerita un estudio mas acabado.

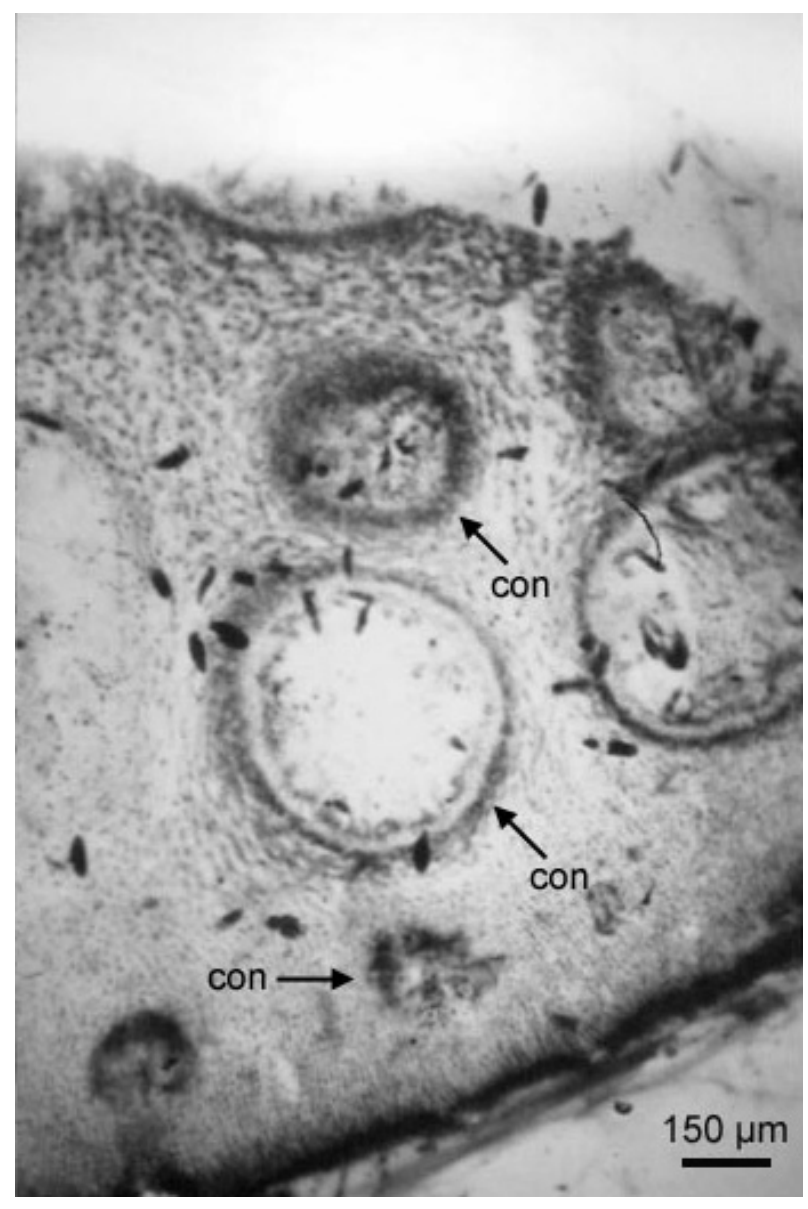

Figura 38

D. antarctica. Corte transversal de una fronda reproductiva con tres estratos de conceptáculos (con), indicando tres períodos reproductivos. $40 \mathrm{x}$

D. antarctica. Transversal section of reproductive frond with three layers of conceptacles (con) showing three reproductive periods. $\mathrm{x} 40$ 


\section{Fenología de la fertilización y embriogénesis}

En los resultados obtenidos se encontraron dos patrones de germinación: uno con patrón asimétrico de germinación (epag) (Figs. 29 y 30) y crecimiento mediante mitosis sucesivas, otro con patrón simétrico de germinación (epsg), crecimiento determinado por alargamiento celular (Fig. 33) con formación de plántulas anormales (Fig. 34). Las diferencias en el patrón de desarrollo de embriones se atribuyen a procesos de ontogénesis normal y anormal respectivamente, estos últimos siempre abortivos. Antecedentes en la literatura de algas pardas indican como embriones normales a aquellos que diferencian rizoide y fronda, como los observados en Fucus donde la polarización de los embriones es indispensable para el desarrollo (LópezRodas \& Costas 1995). En este trabajo se determinó como desarrollo normal indicador post-fecundación positivo a aquel que presenta un patrón de germinación asimétrica (epag) (Figs. 29 y 30) y se determinó como desarrollo anormal indicador post-fecundación negativo a aquel que presenta un patrón de germinación simétrica (epsg) (Figs. 33 y 34) (Tablas 2, 3 y 4).

Aunque el análisis de fenología de maduración de conceptáculos (Fig. 19, Tabla 1) y fertilidad (Tablas 2, 3,4 y 5) fueron efectuados en años diferentes, la presencia de oosferas libres coincide con el período reproductivo propiamente tal y dentro del mismo con el inicio del cese reproductivo de los conceptáculos (Tabla 1 ), en los cuales encontramos ausencia del estado reproductivo inmaduro (1RI) y presencia de ejemplares en maduración (2RI) y maduros (3RM). Los embriones con polaridad simétrica (epsg) encontrados en este período sólo están ausentes al final del período reproductivo (julio/00, agosto/00 y septiembre/00), pero presentes en los dos últimos meses del año anterior (Tablas 3 y 5). Las oosferas con membrana de fecundación (oomf) y los cigotos con polaridad (cp) fueron detectadas en pocas ocasiones, probablemente por ser necesaria una mayor frecuencia de observaciones que las realizadas en este estudio, asumiéndose que cada vez que hubo embriones con polaridad asimétrica o normales (epag) éstas estuvieron presentes.

De acuerdo a los resultados obtenidos en este estudio, una fecundación deficiente o no lograda de las oosferas habría desarrollado procesos de partenogénesis, en todos los casos en que se encontraron embriones anormales (epsg) (Tablas 2, 3 y 5). En embriones de Sargassum se ha obtenido polaridad independientemente de que los huevos estén o no fecundados; la germinación por partenogénesis puede ser inducida por tratamientos hipertónicos. Huevos maduros pero sin fertilizar, mantenidos dos días en agua de mar normal a veces producen un bulbo rizoidal, a pesar de que en ausencia de espermatozoides éstos no prosperan. Esto parece indicar que incluso antes de la fertilización un eje polar es inherente al huevo, pero se ve modificado por eventos posteriores (Nakasawa 1962).

En este estudio, la escasa correlación entre número de cigotos con polaridad (cp) y embriones normales (epag) $(\rho=0.0095)$ podría explicarse por efecto de condiciones de cultivo o por presencia de gametos no completamente viables (inmovilidad de los gametos masculinos). Para que la fecundación sea exitosa debe ocurrir un reconocimiento gamético y acción oportuna y adecuada de las feromonas que controlan el proceso y la plasmogamia (Graham \& Wilcox 2000); si esta sucesión de eventos falla o no es sincrónico, podrían ser la causa de partenogénesis de oosferas y embriones abortivos (epsg) como los observados en esta investigación.

En las pruebas de fertilidad en que se consideró recolección de ejemplares con conceptáculos 2-RI, 3$\mathrm{RM}$, la presencia de distintos patrones de germinación además de poder atribuirse a la existencia de diferentes tamaños de oosferas podrían ser el resultado de estados de madurez subóptimos de las frondas recolectadas (Tabla 3). Al establecerse un paralelo entre los resultados de estados de madurez y fertilidad se observa que en los meses de invierno, la mayoría de los especímenes se encuentran maduros (3-RM) (50-80\%) (Fig. 19) y en los bioensayos de fertilidad realizados se presentan los mayores porcentajes de embriones con patrón asimétrico de germinación (epag) (13-22\%) en los meses de junio/00, julio/00 y agosto/00 (Tabla 3). Sin embargo, en el mes de septiembre/99, que marca el inicio de la primavera y el término del invierno encontrándose un gran porcentaje de ejemplares maduros (70\%) (Fig. 19), los embriones con patrón asimétrico de germinación (epag) fueron menores (5\%) que el patrón simétrico de germinación (epsg) (11\%), pero si se consideran los porcentajes de oosferas con membrana de fertilización (oomf) (13\%), cigotos con polaridad (cp) (2\%) y embriones con patrón asimétrico de germinación (epag) (5\%), estos superan a los con patrón simétrico de germinación (epsg) (11\%), existiendo algún factor que habría afectado en este mes el desarrollo hasta embrión (Tabla 3). A diferencia de lo anterior, en otoño aunque los ejemplares se encuentran maduros (3-RM) (Fig 19), son mayores en las pruebas de fertilidad (Tabla 3 ) los porcentajes de embriones con patrón simétrico de germinación (epsg) (Figs. 33 y 34). Los resultados de los bioensayos de fertilidad in vitro por cruzamiento de suspensiones de gametos de ambos sexos obtenidas separadamente, aunque se efectuaron premeditadamente en la época de madurez, sólo fueron positivos en el mes de mayo/99 y negativos en junio/99 
y julio/99 (Tabla 2) que corresponden a los meses con abundancia de estados (3RM); lo cual determinó suspender este tipo de fertilización y proseguir con pruebas de fertilidad in vitro por cruzamiento de trozos de ambos sexos, lo que se aproxima al proceso natural, ya que es probable que las primeras pruebas hayan estado afectadas por fallas de comunicación hormonal entre gametos femeninos y masculinos, debido a que la inducción de liberación de ellos se realizó separadamente.

De acuerdo a los criterios utilizados en este trabajo, después de la formación de membrana de fertilización en los cigotos y a la detección de dos zonas claras atribuídas a los núcleos de la oosfera y anterozoide respectivamente (Fig. 28), se desarrollaron embriones normales (epag) diferenciados en fronda, estipe y rizoides y embriones anormales (epsg), presumiblemente partenogenéticos sin partes claramente diferenciadas y abortivos. El desarrollo partenogenético de los gametos obtenidos en nuestros resultados, es un fenómeno relativamente común en algas pardas isógamas y anisógamas con gametos femeninos y masculinos flagelados, pero poco usual en especies oógamas, aunque ocurre en algunas Laminariales (Motomura 1991) y Desmarestiales (Wiencke \& Clayton 1990). La partenogénesis fue completamente desconocida en el desarrollo normal de Fucales en los trabajos de Farmer \& Williams 1898, Evans et al. 1982, Callow et al. 1985. Sin embargo, un estudio realizado por Clayton et al. (1998) en Hormosira banksii demostró que huevos no fertilizados exhiben el mismo tipo de desarrollo postfertilización que ocurre en huevos obtenidos por fecundación de gametos. Estos resultados confirmaron que huevos no fecundados de Hormosira son capaces de secretar una pared celular, germinar $y$, en un pequeño número, llevar a cabo divisiones celulares. En Fucales la falta de desarrollo partenogenético ha sido atribuida a la falta de centríolos en los huevos. Los centríolos y el material asociado pericentriolar (centrosomal) tienen un rol vital como centros organizadores de microtúbulos en la formación del huso durante la mitosis de algas pardas (La Claire 1982, Katsaros \& Galatis 1985). Motomura (1994) usando inmunofluorescencia mostró que los centríolos de los cigotos en $F$. distichus, derivaron de los cuerpos basales de los espermios y ellos están ausentes en los huevos no fertilizados, desapareciendo después de la meiosis durante la maduración del huevo. El estudio de partenogénesis en $H$. banksii realizado por Clayton et al. (1998) presenta la primera evidencia de centríolos en huevos de fucoides. En este trabajo, en las pruebas de fertilidad para $D$. antarctica fue común el desarrollo de embriones anormales abortivos (epsg) (Tablas 2, 3 y 5 ).

\section{Observaciones en terreno y distribución geográfica}

Aunque la mayoría de los registros de $D$. antarctica se encuentran principalmente dados para la zona sur y central de Chile, en la zona norte existe uno para Coquimbo en playa Los Vilos $\left(31^{\circ} 58^{\prime} 08^{\prime \prime} 58 \mathrm{~S}, 71^{\circ}\right.$ $\left.32^{\prime} \mathrm{W}\right)$ y otro para la rada de Cobija $\left(22^{\circ} 32^{\prime} 5 \mathrm{~S}, 70^{\circ} 15^{\prime}\right.$ 5W) (Ramírez \& Santelices 1991). En la localidad de Montemar $\left(32^{\circ} 57^{\prime} \mathrm{S}, 71^{\circ} 33^{\prime} \mathrm{W}\right)$, que representaría en parte el límite norte de la distribución de la especie, puede observarse que la presencia de ejemplares intermareales de $D$. antarctica es escasa, $\mathrm{D}=0,1$ ejemplares $/ \mathrm{m}^{2}$ y dispersa entre el cordón dominante de L. nigrescens, a diferencia de la mayor abundancia que se observa en la zona sur, D $=26-30$ ejemplares $/ \mathrm{m}^{2}$ (Westermeier et al. 1994) área que se encuentra en el centro de la distribución geográfica de la especie $\left(39^{\circ}\right.$ $24^{\prime} \mathrm{S}, 73^{\circ} 14^{\prime} \mathrm{O}$ ). Estos antecedentes de la literatura y los resultados obtenidos en los bioensayos realizados en este trabajo, indicarían para la localidad de Montemar, la existencia de factores ambientales límites o adversos para el crecimiento de los embriones; principalmente la temperatura, que para esta localidad, en los años 1997/98, los valores medios fluctuaron entre rangos de $12-13{ }^{\circ} \mathrm{C}$ en otoño, invierno y comienzo de primavera y $14^{\circ}-16^{\circ} \mathrm{C}$ en verano, encontrándose estos en el límite del rango óptimo $\left(11,5-12{ }^{\circ} \mathrm{C}\right)$ definido por Delepine \& Asensi (1976) para el desarrollo de D. antarctica.

Gourdert et al. (2001) señalan para $D$. antarctica del área de la desembocadura del río Biobío, altas densidades de embriones (12300 embriones $/ \mathrm{cm}^{2}$ ) lo cual también confirmaría la hipótesis de que el acercamiento al centro de la distribución geográfica de la especie, optimizaría la densidad de la población de embriones. Hay (1979) sugirió que la temperatura parece ser un factor restrictivo del límite norte de la distribución, mientras que la distribución sur fue abruptamente terminada por el límite norte de la deriva de los hielos. La temperatura superficial del mar puede afectar la capacidad de carga de $D$. antarctica en algunas áreas. Estos valores para $D$. antarctica en las islas Macquarie y Heard son similares aunque la variación en la temperatura del agua es muy amplia. La isla Heard, ubicada bajo la convergencia antárctica, tiene temperaturas del agua en el rango entre $-3 \mathrm{y}+3{ }^{\circ} \mathrm{C}$. La isla Macquarie ubicada al norte de la convergencia antárctica tiene temperaturas superficiales del mar en el rango entre 3 y $8{ }^{\circ} \mathrm{C}$. Las temperaturas del agua en los lugares visitados por Hay (1979) en Nueva Zelanda, presentaron rangos entre 7,5-16 ${ }^{\circ} \mathrm{C}$ y $13-21{ }^{\circ} \mathrm{C}$. Es posible que la alta temperatura del agua en Nueva Zelanda sea subóptima para $D$. antarctica y contribuya a la baja capacidad de carga encontrada (Klemm \& Hallam 1988). Aunque las 
variaciones en temperatura entre las islas Macquarie y Heard son bastante amplias, ellas están en el rango para el crecimiento óptimo de $D$. antarctica y las variaciones en temperatura de Nueva Zelanda y Chile central corresponderían a temperaturas subóptimas. Klemm \& Hallam (1988) determinaron que la capacidad de carga y la densidad numérica de $D$. antarctica de las islas subantarcticas australianas, Macquarie y Heard, es superior al de Nueva Zelanda, sugiriendo que el medio ambiente subantárctico provee mejores condiciones de crecimiento. En este estudio los datos sobre fertilidad in vitro, contribuyen al planteamiento de hipótesis para estudios globales de distribución en este género, necesarios para determinar los factores que afectan la ontogenia de desarrollo de Durvillaea y el medio ambiente óptimo para su crecimiento.

Las observaciones realizadas en terreno, permitieron observar distintas situaciones en el área de caleta Montemar, en el primer semestre del año 2000; al recolectar el material de este estudio no se encontraron reclutas, los escasos ejemplares juveniles que se observaron, por su tamaño $30-60 \mathrm{~cm}$ pertenecerían al reclutamiento de fines de 1999, correspondiéndose con los bajos resultados obtenidos en la germinación de embriones normales, a partir de ejemplares intermareales. En el segundo semestre se evidenciaron especímenes reclutas lo que permite suponer actividad reproductiva en otoño e invierno, hecho que coincide con los mejores resultados de fertilización obtenidos en laboratorio.

La densidad de la población de $D$. antarctica, no es igual en toda el área de muestreo, en general las áreas con mayor exposición al oleaje son las que presentan mayor densidad; esta relación también se observa en poblaciones de $D$. potatorum del sudeste de Australia, en las cuales a medida que aumenta la turbulencia y exposición al oleaje, los niveles de densidad y biomasa son mayores (Cheshire \& Hallam 1988). En la localidad de Montemar las áreas con menor densidad además de tener una menor exposición al oleaje, presentan un alto grado de competencia por el espacio con el alga Lessonia que aquí es predominante. Durvillaea y Lessonia son encontradas frecuentemente creciendo en las mismas costas y es posible que esta última especie pueda también crecer en South Georgia (Hay 1988). Skottsberg (1941) describió a Lessonia como conspicuamente ausente de South Georgia y Papenfuss (1964) excluyó a esta isla del rango de distribución geográfica del género. Sin embargo, al igual que Durvillaea es incierto que Lessonia se presente en las localidades expuestas al oleaje examinadas por Skottsberg (Hay 1988).

Los datos obtenidos con la estimación del tamaño de la población de $D$. antarctica en dos períodos de tiempo, permiten confirmar apreciaciones empíricas de disminución de la población, hecho que no debería ocurrir por tratarse de un área protegida; podemos decir que en los últimos cinco años la población ha disminuido alrededor de un tercio. Esta disminución puede tener varias causas, por ejemplo: fenómenos climáticos, eventos El Niño (1997/98), herbivoría, predación humana, contaminación y la variación propia y natural que tendría esta población por encontrarse en el límite de su distribución geográfica, hecho antes no considerado.

El período reproductivo de $D$. antarctica de la localidad de Montemar, en meses más fríos, concuerda con lo expresado por Delepine \& Asensi (1976) quienes señalan una extrema dependencia de temperaturas por bajo $12{ }^{\circ} \mathrm{C}$, lo cual hace a los gametos de esta especie poco viables, tratándose por tanto de una especie propia de aguas subantárcticas. Esto indica para la localidad de Montemar una posición geográfica en el rango del límite norte de la distribución geográfica.

Los conocimientos obtenidos sobre la historia de vida de $D$. antarctica constituyen bases biológicas importantes en planes de manejo del recurso y en la implementación de períodos de vedas para la protección de la especie.

\section{Agradecimientos}

Este estudio fue posible gracias al financiamiento del proyecto de la Dirección de Investigación de la Universidad de Valparaíso, DIUV 05 - 96. Sinceros agradecimientos al equipo de edición de la Revista de Biología Marina y Oceanografía.

\section{Literatura Citada}

Alveal K 1970. Estudios ficoecológicos en la región costera de Valparaíso. Revista de Biología Marina, Valparaíso, 14 (1): $7-88$.

Alveal K, A Candia, G Collantes, M Edding, E Fonk, C Melo, A Poblete, P Rivera, H Romo, C Werlinger \& R Westermeier. 1990a. Situación de desarrollo y explotación de los recursos algales de Chile. Red Algas Marinas - Chile. CIID, Canadá 79p.

Alveal K, A Candia, G Collantes, M Edding, E Fonk, C Melo, A Poblete, P Rivera, H Romo, C Werlinger \& R Westermeier. 1990b. Guía de algas marinas chilenas de importancia económica. Red Algas Marinas - Chile. CIID, Canadá 114 p.

Buschmann A. 1982. Biología de Durvillaea antarctica (Phaeophyta, Durvilleales) en Chile Centro Sur. Morfología y reproducción. Informe de Unidad de 
Investigación para optar al Grado de Licenciado en Biología Marina. Universidad de Concepción, Chile 26 p.

Bustamante RH \& JC Castilla. 1990. Impact of human exploitation of the intertidal southern bull-kelp Durvillaea antarctica (Phaeophyta, Durvilleales) in Central Chile. Biological Conservation 52: $205-220$.

Callow JA, Callow ME \& LV Evans. 1985. Fertilization in Fucus. En: Metz, CB \& Monroy, A (eds), Biology of fertilization 389 - 407. Academic Press, London.

Callow ME, LV Evans, GP Bolwell \& JA Callow. 1978. Fertilization in brown algae. I. SEM and others observations in Fucus serratus Journal Cell Science 32: 45 $-54$.

Castilla JC \& RH Bustamante. 1989. Human exclusion from rocky intertidal of Las Cruces, Central Chile: effects on Durvillaea antarctica (Phaeophyta, Durvilleales). Marine Ecology Progress Series 50: 203 - 214.

Cheshire A \& JC Conran. 1995. A cladistic analysis of the evolution and biogeography of Durvillaea (Phaeophyta). Journal of Phycology 31: $644-655$.

Cheshire A \& N Hallam. 1988. Biomass and density of native stands of Durvillaea potatorum (southern bull-kelp) in south eastern Australia. Marine Ecology Progress Series 48: $277-283$.

Choris L. 1822. Voyage pittoresque autour du monde. Part I. $\mathrm{Vi}+17$ pp., 12 pls. Paris.

Clayton MN, Hallam ND \& CM Shankly. 1987. The seasonal pattern of conceptacle development and gamete maturation in Durvillaea potatorum (Durvillaeales, Phaeophyta). Phycologia 26 (1) 35 - 45.

Clayton MN \& CM Ashburner. 1994. Secretion of phenolic bodies following fertilization in Durvillaea potatorum (Durvillaeales, Phaeophyta). European Journal of Phycology 29: $1-9$.

Clayton MN, K Kevekordes, MEA Schoenwaelder, CE Schmid \& CM Ahsburner. 1998. Parthenogenesis in Hormosira banksii (Fucales, Phaeophyceae). Botanica Marina 41: 23 - 30 .

Collantes G, R Riveros \& M Acevedo. 1997. Fenología reproductiva de Durvillaea antarctica (Phaeophyta, Durvillaeales) del intermareal de caleta Montemar, Chile central. Revista de Biología Marina y Oceanografía 32 (2): 11- 116 .

Costas E, A Aguilera, S González-Gil \& V Lopez-Rodas. 1994. Early development in Fucus spiralis: analysis of surface glycan moieties and cell differentiation using lectins. Botanica Marina 37: 11 - 15 .

Delepine $\mathbf{R}$ \& A Asensi. 1976. Quelques données experimentales sur l'écophysiologie de Durvillea antarctica (Cham.) Hariot (Phéophycées). Société Phycologique de France, Bulletin 21: 65 - 80.
Evans LV, JA Callow \& ME Callow. 1982. The biology and biochemistry of reproduction and early development in Fucus. Progress Phycological Research 1: 68 - 110.

Farmer JB \& JL Williams. 1898. Contributions to our knowledge of the Fucaceae: their life history and citology. Philosophical Transactions of the Royal Society of London, Series B 189: 623- 645.

Gourdet C, K Alveal \& P Celis. 2001. Desarrollo inicial de Durvillaea antarctica en sustratos artificiales. Resúmen 43, XXI Congreso de Ciencias del Mar, Viña del Mar, Chile.

Graham LE \& LW Wilcox. 2000. Algae. Prentice Hall Upper Saddle River, NJ 07458, 640 pp.

Guiler EP. 1959. The intertidal ecology of Montemar area, Chile. Papers \& Proceedings of the Royal Society of Tasmania 93: 165 - 183.

Hariot P. 1892. Complément a la flore algologique de la Terre de Feu. Notarisia $7: 1427$ - 1435.

Hardy F G \& BL Moss. 1978. The attachment of zygotes and germlings of Halidrys siliquosa (L.) Lyngb. (Phaeophyceae, Fucales ). Phycologia 17: 69 - 78.

Hay CH. 1979. Nomenclature and taxonomy within the genus Durvillaea Bory (Phaeophyceae: Durvilleales Petrov). Phycologia 18 (3): 191 - 202.

Hay C. 1988. The occurrence of Durvillaea antarctica (Durvillaeales, Phaeophyta) at South Georgia, South Atlantic Ocean. Phycologia 27 (3): $424-427$.

Katsaros C \& B Galatis. 1985. Ultrastructural studies on thallus development in Dictyota dichotoma ( Phaeophyta, Dictyotales). British Phycological Journal 20: 263 - 276.

Klemm MF \& ND Hallam 1988. Standing crop of Durvillaea antarctica (Chamisso) Hariot (Phaeophyta) on the Australian sub- Antarctic Macquarie and Heard islands. Phycologia 27 (4):505- 509.

Kropf DL, B Kloareg \& R Quatrano. 1988. Cell wall is required for fixation of the embryonic axis in Fucus zygotes. Science 239: 187-189.

La Claire JW. 1982. Light and electron microscopic studies of growth and reproduction in Cutleria (Phaeophyta). Phycologia 21: 273 - 287.

Lagos V. 2001. Fertilidad in vitro de Durvillaea antarctica (Chamisso) Hariot, (Phaeophyta, Durvillaeales). Tesis, Carrera de Biología Marina, Facultad de Ciencias del Mar, Universidad de Valparaíso 85 pp.

Longo FJ, JW Lynn, DH McCulloh \& EL Chambers. 1986. Correlative ultrastructural and electrophysiological studies of sperm-egg interactions of the sea urchin, Lytechinus variegatus. Developmental Biology 118: 155 166.

Lopez- Rodas V \& E Costas. 1995. Morphometrical analysis of early development in Fucus spiralis L. (Phaeophyta). Revista Biología Marina, Valparaiso 30 (1): 45 - 56. 
Maier I \& MN Clayton. 1989. Oogenesis in Durvillaea potatorum (Durvillaeales, Phaeophyta). Phycologia 28 (2): $271-274$.

Manton I. 1964. A contribution towards understanding of "the primitive fucoid". New Phytologist 63: 244 - 252.

Merino A. 2000. Estados de madurez en Durvillaea antarctica (Chamisso) Hariot, (Phaeophyta, Durvillaeales). Tesis, Carrera de Biología Marina, Facultad de Ciencias del Mar, Universidad de Valparaíso $63 \mathrm{pp}$.

Motomura T. 1991. Inmunofluorescence microscopy of fertilization and parthenogenesis in Laminaria angustata (Phaeophyta). Journal of Phycology 27: 248 - 257.

Motomura T. 1994. Electron and immunofluorescence microscopy on the fertilization of Fucus distichus (Fucales, Phaeophyceae). Protoplasma 178: 97 - 110.

Müller DG \& NM Luthe 1981. Hormonal interaction in sexual reproduction of Desmarestia aculeata (Phaeophyceae). British Phycological Journal 16 (4): 351 -356 .

Müller DG, MN Clayton, G Gasmann, W Boland, FJ Marner, T Schotten \& L Jaenicke. 1985. Cystophorene and hormosirene, sperm attractans in Australian brown algae. Natur wissenchaften 72: 97 - 98.

Nakasawa S. 1962. Polarity. En : Lewin RA (ed), Physiology and Biochemistry of Algae: 653-661. Academic Press New York.

Naylor M. 1953. The New Zealand species of Durvillea. Transactions of the Royal Society of New Zealand 80 $(3,4): 277$ - 297.

Nizamuddin M. 1968. Observations on the Order Durvilleales J. Petrov 1965. Botanica Marina Vol. XI, Fasc. 1-4: 115 117.

Norambuena R. 1996. Recent trends of seaweed production in Chile. Hydrobiologia 326/327: 371 - 379.

Pak N \& H Araya. 1996. Valor nutritivo y aportes de fibra dietética (soluble e insoluble) de macro algas marinas comestibles de Chile, crudas y cocidas. Alimentos 21: 1.2. $63-69$.

Papenfuss GF. 1964. Catalogue and bibliography of Antarctic and Subantarctic benthic marine algae. Antarctic Research. Series. 1: $1-76$.

Paredes A. 1998. Estudios ultraestructurales de la oogénesis, espermatogénesis, fecundación y embriogénesis temprana de Durvillaea antarctica (Chamisso) Hariot, (Phaeophyta, Durvillaeales). Tesis, Carrera de Biología Marina, Instituto de Oceanología, Universidad de Valparaíso 97 pp.

Petrov JE. 1965. De positione familiae Durvilleacearum et systematica classis Cyclosporophycearum (Phaeophyta). Novit. Syst. Plant. Non Vascularium 1965: 70 - 72.
Petrov JE. 1967. The development of conceptacles (scaphidia) in Ascophyllum nodosum and Durvillea antarctica (Chamisso) Hariot. Bot. Zh. SSSR 52: $348-$ 350 .

Pollock EG. 1970. Fertilization in Fucus. Planta (Berl.) 92: 85 -99 .

Quatrano RS. 1972. An ultraestructural study of determined site of rhizoid formation in Fucus zygotes. Experimental Cell Research 70: $1-12$.

Quatrano RS \& PT Stevens. 1976. Cell wall assembly in Fucus zygotes. I. Characterization of the polysaccharide components. Plant Physiology 58: 224 - 231.

Quatrano RS. 1980. Gamete release, fertilization, and embryogenesis in the Fucales. En: Gantt E (ed), Handbook of Physiological Methods: 60 - 68. Cambridge University Press, London.

Quatrano RS \& SL Shaw. 1997. Role of the cell wall in the determination of cell polarity and the plane of cell division in Fucus embryos. Trends in Plant Science 2 (1): 15 - 21.

Ramírez ME \& B Santelices. 1991. Catálogo de las algas marinas bentónicas de la costa temperada del Pacífico de Sudamérica. Monografías Biológicas. Publicaciones Periódicas Pontificia Universidad Católica de Chile. Vicerrectoría Académica 5; 437p.

Ricker RW. 1987. Taxonomy and Biogeography of Macquarie Island Seaweeds. British Museum (Natural History), London, 344 pp.

Roberts M. 1979. Observations on cell structure and cytology in the genus Durvillaea Bory. New Zealand Journal of Botany 17: 241 - 249.

Santelices B, J Cancino, S Montalva, $\mathbf{R}$ Pinto \& $\mathbf{E}$ González. 1977. Estudios ecológicos en la zona costera afectada por contaminación del "Northern Breeze". II Comunidades de playas de rocas. Medio Ambiente 2: $65-$ 83.

Santelices B. 1989. Algas marinas de Chile. Distribución, ecología, utilización y diversidad, 399 p. Ediciones Universidad Católica de Chile. Santiago, Chile .

Santelices B, JC Castilla, J Cancino \& P Schmiede. 1980. Comparative ecology of Lessonia nigrescens and Durvillaea antarctica (Phaeophyta) in Central Chile. Marine Biology 19: 119 - 132.

Schuel H. 1978. Secretory functions of egg cortical granules in fertilization and development. Gamete Research. 1. 299 -382 .

SERNAP. 1994. Anuario Estadístico de Pesca 1994. Servicio Nacional de Pesca. Valparaíso, Chile, 236 p.

SERNAP. 1999. Anuario Estadístico de Pesca 1999. Servicio Nacional de Pesca. Valparaíso, Chile, 297 p. 
Skottsberg C. 1941. Communities of marine algae in Subantartic and Antarctic Waters Kongliga Svenska Vetenskap Akademiens Handlingar, Series 3, 19, (4):1 92.

Smith DC 1955. Cryptogamic Botany. Vol I. McGraw-Hill, New York, ix $+546 \mathrm{p}$.

Sokal RR \& FJ Rohlf. 1979. Biometría: principios y métodos estadísticos en la investigación biológica, H. Blume, Madrid, España, 880 pp.

Vreeland V, J Herbert \& L Epstein. 1998. Polyphenols and oxidases in substratum adhesion by marine algae and mussels. Journal of Phycology 34: $1-8$.

Westermeier R, DG Muller, I Gomez, P Rivera \& H Wenzel. 1994. Population biology of Durvillaea antarctica and Lessonia nigrescens (Phaeophyta) on the rocky shores of southern Chile. Marine Ecology Progress Series 110: 187-194.
Wiencke C \& MN Clayton. 1990. Sexual reproduction, life history, and early development in culture of the Antarctic brown algae Himantothallus grandifolius (Desmarestiales, Phaeophyceae). Phycologia 29: 9-18.

Wright P, J Green \& J Callow. 1995a. The Fucus (Phaeophyceae) sperm receptor for eggs. I. Development and characteristic of a binding assay. Journal of Phycology 31: $584-591$.

Wright P, J Callow \& J Green. 1995b. The Fucus (Phaeophyceae) sperm receptor for eggs. II. Isolation of a binding protein which partially activates eggs. Journal of Phycology 31: $592-600$. 